\title{
Regional Electric-Power Systems Planning and Carbon Dioxide Emissions Management under Uncertainty
}

\author{
Y.F. Li, Y.P. Li ${ }^{*}$ and G.H. Huang \\ MOE Key Laboratory of Regional Energy Systems Optimization, Sino-Canada Resources and Environmental \\ Research Academy, North China Electric Power University, Beijing 102206, China
}

\begin{abstract}
In this study, an interval two-stage integer programming model is formulated for planning electric-power systems and managing carbon dioxide $\left(\mathrm{CO}_{2}\right)$ emissions under uncertainty. The developed model can reflect dynamic, interactive, and uncertain characteristics of regional energy systems. Besides, the model can be used for answering questions related to types, times, demands and mitigations of energy systems planning practices, with the objective of minimizing system cost over a long-time planning horizon. The developed model is also applied to a case study of planning $\mathrm{CO}_{2}$-emission mitigation for an electric-power system that involves fossil-fueled and renewable energy sources. Solutions can help generate electricity-generation schemes and capacity-expansion plans under different $\mathrm{CO}_{2}$-mitigation options and electricity-demand levels. Different $\mathrm{CO}_{2}$-emission management policies corresponding to different renewable energy development plans are analyzed. A high system cost will increase renewable energy supply and reduce $\mathrm{CO}_{2}$ emission, while a desire for a low cost will run into risks of a high energy deficiency and a high $\mathrm{CO}_{2}$ emission.
\end{abstract}

Keywords: $\mathrm{CO}_{2}$ emission, electric-power systems, optimization, planning, renewable energy, uncertainty analysis.

\section{INTRODUCTION}

Carbon dioxide $\left(\mathrm{CO}_{2}\right)$ is the prominent greenhouse gas (GHG) that leads to global warming and climatic change with increasing concentrations above preindustrial levels [1-3]. Current annual emissions now exceed $30 \mathrm{Gt} / \mathrm{y}$ of $\mathrm{CO}_{2}$, while atmospheric $\mathrm{CO}_{2}$ levels recently exceeded 400 ppm [4]. In the World average, the electricity sector is likely to play a pivotal role in reducing $\mathrm{CO}_{2}$ emissions. Because electricity can be produced by various ways such as fossil fuel burning, nuclear fission and by harnessing of various carbonfree renewable energy resources, there are strong options for carbon mitigation in electricity sector, with different socio-environmental costs and benefits [1-4]. Therefore, innovative planning, adaptation, and mitigation approaches as well as policies for sustainable electric-power systems management are desired.

However, electric-power systems planning and $\mathrm{CO}_{2}$ emissions management efforts are complicated with a variety of uncertainties due to parameter estimation, input data, and model structure, which may affect the relevant optimization analyses and thus the associated decision-making process [5]. Uncertainties can be derived from energy-related processes and activities (e.g. exploration/exploitation, conversion/processing, and supply/demand); uncertainties can also arise due

*Address correspondence to this author at the MOE Key Laboratory of Regional Energy Systems Optimization, Sino-Canada Resources and Environmental Research Academy, North China Electric Power University, Beijing 102206, China; Tel: +86 106177 3887; Fax: +86 106177 3885; E-mail: yongping.li@iseis.org, yongpingli33@163.com to human-induced imprecision or fuzziness, such as lack of available data and biased judgments (or preferences) in assigning priority factors (weighting levels) to multiple management objectives. The inherent complexity and uncertainty that exist in electric-power systems planning have essentially placed them beyond the conventional deterministic optimization methods [5].

As a result, a number of energy systems planning models, which could facilitate reflection of such complexities as well as analyze tradeoffs between emission mitigation and cost minimization, were developed based on two-stage stochastic programming (TSP) approaches [6-12]. TSP had advantages in reflecting complexities of system uncertainties as well as analyzing policy scenarios when the pre-regulated targets were violated. In TSP, the first-stage decision is to be made before uncertain information is revealed, whereas the second-stage one (recourse) is to adapt to the previous decision based on the further information; the second-stage decision is used to minimize 'penalties' that may appear due to any infeasibility [5, 13-15]. Nürnberg and Römisch [6] developed a twostage stochastic programming model for the short- or mid-term cost-optimal electric power production planning, considering the power generation in a hydrothermal generation system under uncertainty in demand (or load) and prices for fuel and delivery contracts. Lin et al. [10] developed a hybrid intervalfuzzy two-stage stochastic energy systems planning model to deal with uncertainties that can be expressed as fuzzy numbers, probability distributions, and discrete intervals. Lin and Huang [11] proposed an in exact two- 
stage stochastic energy systems planning model for managing greenhouse gas emission at a municipal level, where GHG-emission reduction target was treated as random variable. Chen et al. [12] discussed $\mathrm{CO}_{2^{-}}$emission trading scheme with an integrated energy system using interval two-stage stochastic programming, which could deal with uncertainties expressed as discrete intervals and random variables. The previous studies emphasized on the planning of either electric power systems or entire energy systems by regarding the $\mathrm{CO}_{2}$ emissions management as a single constraint. Studies on how to apply various carbon-free renewable energy technologies to adjust the electricity generating structure, however, have hardly been covered in their models. There are many ways to generate electricity, and this flexibility gives the electricity sector a major advantage in responding to changes in market incentives to encourage carbon-free technologies [16].

Therefore, an interval two-stage integer programming model will be formulated for managing $\mathrm{CO}_{2}$ emissions within an electric-power system over a long-time planning horizon. This paper will be organized as follows: Section 2 describes the interval two-stage integer programming method; Section 3 provides a case study of managing $\mathrm{CO}_{2}$ emissions in electric-power systems through the proposed method; Section 4 presents result analysis, where a number of scenarios based on different $\mathrm{CO}_{2}$-mitigation options and energy-demand levels are analyzed; Section 5 draws some conclusions.

\section{METHODOLOGY}

Two-stage stochastic programming (TSP) method is effective for problems where an analysis of policy scenarios is desired and the related data are mostly uncertain. In TSP, decision variables are divided into two subsets: those that must be determined before random variables are disclosed, and those (recourse variables) that will be determined after the uncertainties are disclosed. A general TSP model can be formulated as follows $[17,18]$ :

$\mathrm{Z}=\min C^{T} X+E_{\omega \in \Omega}[Q(X, \omega)]$

subject to:

$x \in X$

with

$Q(x, \omega)=\min f(\omega)^{T} y$ subject to:

$D(\omega) y \geq h(\omega)+T(\omega) x$

$y \in Y$

where $X \subseteq R^{n_{1}}, C \subseteq R^{n_{1}}$, and $Y \subseteq R^{n_{2}}$. Here, $\omega$ is a random variable from space $(\Omega, F, P)$ with $\Omega \subseteq R^{k}$, $f: \Omega \rightarrow R^{n_{2}}, \quad h: \Omega \rightarrow R^{m_{2}}, \quad D: \Omega \rightarrow R^{m_{2} \times n_{2}}, \quad$ and $T: \Omega \rightarrow R^{m_{2} \times n_{1}}$. By letting random variables (i.e. $\omega$ ) take discrete values $\omega_{h}$ with probability levels $p_{h}\left(h=1,2, \ldots, v\right.$ and $\left.\sum p_{h}=1\right)$, the above TSP can be equivalently

formulated as a linear programming model as follows [17-19]:

$\operatorname{Min} f=C_{T_{1}} X+\sum_{h=1}^{v} p_{h} D_{T_{2}} Y$

subject to:

$A_{r} X \leq B_{r}, r=1,2, \ldots, m_{1}$

$A_{t} X+A_{t}^{\prime} Y \geq w_{h}, t=1,2, \ldots, m_{2} ; h=1,2, \ldots, v$

$x_{j} \geq 0, x_{j} \in X, j=1,2, \ldots, n_{1}$

$y_{j h} \geq 0, y_{j h} \in Y, j=1,2, \ldots, n_{2} ; h=1,2, \ldots, v$

Obviously, model (2) can deal with uncertainties in the right-hand sides presented as probability distributions when coefficients in the left-hand sides and in the objective function are deterministic. However, in real-world optimization problems, the quality of information that can be obtained is mostly not satisfactory enough to be presented as probabilities [17]. Such complexities cannot be solved through model (2).

Interval mathematical programming (IMP) is effective in tackling uncertainties expressed as interval values with known lower and upper bounds but unknown distribution functions [20]. Moreover, mixed integer linear programming (MILP) technique is used for facilitating dynamics analysis of the timing, sizing and siting in terms of capacity expansions. Therefore, through incorporating IMP, MILP and TSP within a general optimization framework, an interval two-stage integer programming (ITSIP) model can be formulated as follows: 
$\operatorname{Min} f^{ \pm}=C_{T_{1}}^{ \pm} X+\sum_{h=1}^{v} p_{h} D_{T_{2}}^{ \pm} Y^{ \pm}$

subject to:

$A_{r}^{ \pm} X^{ \pm} \leq B_{r}^{ \pm}, r=1,2, \ldots, m_{1}$

$A_{t}^{ \pm} X^{ \pm}+A_{t}^{ \pm \pm} Y^{ \pm} \geq w_{h}^{ \pm}, t=1,2, \ldots, m_{2} ; h=1,2, \ldots, v$

$x_{j}^{ \pm} \geq 0, x_{j}^{ \pm} \in X^{ \pm}, j=1,2, \ldots, n_{1}$

$y_{j h}^{ \pm} \geq 0, y_{j h}^{ \pm} \in Y^{ \pm}, j=1,2, \ldots, n_{2} ; h=1,2, \ldots, v$

where $A_{r}^{ \pm} \in\left\{R^{ \pm}\right\}^{m_{1} \times n_{1}}, \quad A_{t}^{ \pm} \in\left\{R^{ \pm}\right\}^{m_{2} \times n_{2}}, \quad B_{r}^{ \pm} \in\left\{R^{ \pm}\right\}^{m_{1} \times 1}$, $C_{T_{1}}^{ \pm} \in\left\{R^{ \pm}\right\}^{1 \times n_{1}}, D_{T_{2}}^{ \pm} \in\left\{R^{ \pm}\right\}^{1 \times n_{2}}, X^{ \pm} \in\left\{R^{ \pm}\right\}^{n_{1} \times 1}, Y^{ \pm} \in\left\{R^{ \pm}\right\}^{n_{2} \times 1}$ and $\left\{R^{ \pm}\right\}$denote a set of interval parameters and/or variables; superscripts '-' and '+' represent lower and upper bounds of the interval values, respectively. In model (3), decision variables can be sorted into two categories: continuous and binary. Model (3) can be transformed into two deterministic sub models that correspond to the lower and upper bounds of desired objective function value. This transformation process is based on an interactive algorithm, which is different from the best/worst case analysis [20]. Interval solutions can then be obtained by solving the two sub models sequentially. The sub model corresponding to the lower-bound objective function value $\left(f^{-}\right)$can be firstly formulated as follows (assume that $B^{ \pm}>0$, and $\left.f^{ \pm}>0\right)$ :

$\operatorname{Min} f^{-}=\sum_{j=1}^{k_{1}} c_{j}^{-} x_{j}^{-}+\sum_{j=k_{1}+1}^{n_{1}} c_{j}^{-} x_{j}^{+}+$

$\sum_{j=1}^{k_{2}} \sum_{h=1}^{v} p_{j h} d_{j}^{-} y_{j h}^{-}+\sum_{j=k_{2}+1}^{n_{2}} \sum_{h=1}^{v} p_{j h} d_{j}^{-} y_{j h}^{+}$

subject to:

$\sum_{j=1}^{k_{1}}\left|a_{r j}\right|^{+} \operatorname{Sign}\left(a_{r j}^{+}\right) x_{j}^{-}+\sum_{j=k_{1}+1}^{n_{1}}\left|a_{r j}\right|^{-} \operatorname{Sign}\left(a_{r j}^{-}\right) x_{j}^{+} \leq b_{r}^{+}, \forall r$

$\sum_{j=1}^{k_{1}}\left|a_{t j}\right|^{+} \operatorname{Sign}\left(a_{t j}^{+}\right) x_{j}^{-}+\sum_{j=k_{1}+1}^{n_{1}}\left|a_{t j}\right|^{-} \operatorname{Sign}\left(a_{t j}^{-}\right) x_{j}^{+}$

$+\sum_{j=1}^{k_{2}}\left|a_{t j}^{\prime}\right|^{+} \operatorname{Sign}\left(a_{t j}^{\prime+}\right) y_{j h}^{-}+\sum_{j=k_{2}+1}^{n_{2}}\left|a_{t j}^{\prime}\right|^{-} \operatorname{Sign}\left(a_{t j}^{\prime-}\right) y_{j h}^{+} \geq w_{h}^{-}, \forall t, h$

$x_{j}^{-} \geq 0, j=1,2, \ldots, k_{1}$ $x_{j}^{+} \geq 0, j=k_{1}+1, k_{1}+2, \ldots, n_{1}$

$y_{j h}^{-} \geq 0, \forall h ; j=1,2, \ldots, k_{2}$

$y_{j h}^{+} \geq 0, \forall h ; j=k_{2}+1, k_{2}+2, \ldots, n_{2}$

where $x_{j}^{ \pm}, j=1,2, \ldots, k_{1}$, are interval variables with positive coefficients in the objective function; $x_{j}^{ \pm}$, $j=k_{1}+1, k_{1}+2, \ldots, n_{1}$ are interval variables with negative coefficients; $y_{j h}^{ \pm}, j=1,2, \ldots, k_{2}$ and $h=1,2, \ldots, v$ are random variables with positive coefficients in the objective function; $y_{j h}^{ \pm}, \quad j=k_{2}+1, k_{2}+2, \ldots, n_{2} \quad$ and $h=1,2, \ldots, v$ are random variables with negative coefficients. Solutions of $x_{j \text { opt }}^{-}\left(j=1,2, \ldots, k_{1}\right), x_{j \text { opt }}^{+}\left(j=k_{1}+1, k_{1}+2, \ldots, n_{1}\right), y_{j h \text { opt }}^{-}$ $\left(j=1,2, \ldots, k_{2}\right)$, and $y_{j h \text { opt }}^{+}\left(j=k_{2}+1, k_{2}+2, \ldots, n_{2}\right)$ can be obtained through sub model (4). Based on theabove solutions, the second sub model for $f^{+}$can be formulated as follows:

$\operatorname{Min} f^{+}=\sum_{j=1}^{k_{1}} c_{j}^{+} x_{j}^{+}+\sum_{j=k_{1}+1}^{n_{1}} c_{j}^{+} x_{j}^{-}+\sum_{j=1}^{k_{2}} \sum_{h=1}^{v} p_{j h} d_{j}^{+} y_{j h}^{+}$

$+\sum_{j=k_{2}+1}^{n_{2}} \sum_{h=1}^{v} p_{j h} d_{j}^{+} y_{j h}^{-}$

subject to:

$\sum_{j=1}^{k_{1}}\left|a_{r j}\right|^{-} \operatorname{Sign}\left(a_{r j}^{-}\right) x_{j}^{+}+\sum_{j=k_{1}+1}^{n_{1}}\left|a_{r j}\right|^{+} \operatorname{Sign}\left(a_{r j}^{+}\right) x_{j}^{-} \leq b_{r}^{-}, \forall r$

$\sum_{j=1}^{k_{1}}\left|a_{t j}\right|^{-} \operatorname{Sign}\left(a_{t j}^{-}\right) x_{j}^{+}+\sum_{j=k_{1}+1}^{n_{1}}\left|a_{t j}\right|^{+} \operatorname{Sign}\left(a_{t j}^{+}\right) x_{j}^{-}$

$+\sum_{j=1}^{k_{2}}\left|a_{t j}^{\prime}\right|^{-} \operatorname{Sign}\left(a_{t j}^{\prime-}\right) y_{j h}^{+}+\sum_{j=k_{2}+1}^{n_{2}}\left|a_{t j}^{\prime}\right|^{+} \operatorname{Sign}\left(a_{t j}^{\prime+}\right) y_{j h}^{-} \geq w_{h}^{+}, \forall t, h$

$x_{j}^{+} \geq x_{j \mathrm{opt}}^{-}, j=1,2, \ldots, k_{1}$

$0 \leq x_{j}^{-} \leq x_{j \text { opt }}^{+}, j=k_{1}+1, k_{1}+2, \ldots, n_{1}$

$y_{j h}^{+} \geq y_{j h \mathrm{opt}}^{-}, \forall h ; j=1,2, \ldots, k_{2}$

$0 \leq y_{j h}^{-} \leq y_{j h \mathrm{opt}}^{+}, \forall h ; j=k_{2}+1, k_{2}+2, \ldots, n_{2}$

Solutions of $\quad x_{j \mathrm{opt}}^{+} \quad\left(j=1,2, \ldots, k_{1}\right), \quad x_{j \mathrm{opt}}^{-}$ $\left(j=k_{1}+1, k_{1}+2, \ldots, n_{1}\right), y_{j h \text { opt }}^{+} \quad\left(j=1,2, \ldots, k_{2}\right), \quad$ and 
$y_{\text {jh opt }}^{-}\left(j=k_{2}+1, k_{2}+2, \ldots, n_{2}\right)$ can be obtained through sub model (5). Through integrating solutions of sub models (4) and (5), interval solution for model (3) can be expressed as follows:

$x_{j \text { opt }}^{ \pm}=\left[x_{j \text { opt }}^{-}, x_{j \text { opt }}^{+}\right], \forall j$

$y_{j h \mathrm{opt}}^{ \pm}=\left[y_{j h \mathrm{opt}}^{-}, y_{j h \mathrm{opt}}^{+}\right], \forall j, h$

$f_{\mathrm{opt}}^{ \pm}=\left[f_{\mathrm{opt}}^{-}, f_{\mathrm{opt}}^{+}\right]$

\section{CASE STUDY}

\subsection{Overview of the Study System}

Consider an electric-power system where local decision makers are responsible for supplying electric power to multiple end users over a long-term planning horizon. A number of power-conversion technologies are available for installation to meet electricity demand in each period. Since different technologies have diverse conversion efficiencies, $\mathrm{CO}_{2}$ emissions, capital investments, and operation costs, they compete with each other to supply a mixture of options to end users. The existing electric utilities include coal-fired, natural gas-fired, petroleum-fired, hydropower, wind power and solar power facilities. The electricity demand would rise with the economy development and population growth. Thus the planners are forced to decide whether new electric-power utilities (hydropower, wind power and solar power facilities) should be established. The second measure is to expand the existing electricpower utilities to satisfy the increasing demand. Energy strategy and policy are strongly driven by the twin objectives of sustainability (including environmental aspects) and security of energy supply. The utilization of energy resources is restrained by source availabilities, high costs of new technologies, as well as environmental and $\mathrm{CO}_{2}$ concerns. On one hand, increasing concentration of $\mathrm{CO}_{2}$ emitted from fossil fuel combustion is likely to accelerate the rate of global warming. Consequently, less fossil fuel consumptions and more renewable energy resources (e.g. hydro, wind and solar) are utilized to satisfy increasing energy demand and $\mathrm{CO}_{2}$ reduction requirement. On the other hand, availabilities of renewable energy resources (e.g. hydro and wind) are highly dependent on meteorological conditions that fluctuate within a certain range due to climate change. Such variations of renewable energy availabilities would then affect operating statuses of relevant facilities, resulting in changes in their energy outputs [13-15].
The study system is complicated with uncertainties related to various economic and technical parameters as well as the process of energy demand/supply, conversion, transmission, consumption, $\mathrm{CO}_{2}$-emission inventory control measures. In this study, potential energy demand may vary with the population increase and economic development, which can be expressed as random variable with a given probability level in one case and the other uncertain parameters may be expressed as intervals (e.g. generation target, cost and benefit parameters, $\mathrm{CO}_{2}$-emission permit, pollutant control capacity); besides, the relevant electricitygeneration plan would be of dynamic features and a pre-regulated policy is desired [13-15].

In the study system (as shown in Figure 1), six kinds of power conversion technologies are considered, including coal-fired power, gas-fired power, petroleum-fired power, hydropower, wind power and solar power conversion technologies. The planning horizon is 15 years, which is further divided into three 5 -year periods. The end-user's random electricity demands and electricity generation targets of each power conversion technology are presented in Table 1. The peak load demands are [1.5, 3.0], [2.0, 3.5] and $[2.5,4.0] \mathrm{GW}$ in periods 1,2 and 3 , respectively. Table 2 provides the economic and technological datum of each power conversion technology. Each technology has a residual capacity; coal-fired power has a residual capacity of $1 \mathrm{GW}$, natural gas-fired power has a residual capacity of $0.22 \mathrm{GW}$, petroleum-fired power has a residual capacity of $0.15 \mathrm{GW}$, hydropower has a residual capacity of $0.28 \mathrm{GW}$ but the initial capacity of wind power and solar power are all 0 . The representative costs and technical data were investigated based on governmental reports and other related literature $[10-15,21]$.

Two measures are used to reduce the amount of $\mathrm{CO}_{2}$ emissions for three fossil-fueled power plants: (i) capture and storage (CS), and (ii) chemical absorption

(CA). In order to meet the increasing electricity demand, $\mathrm{CO}_{2}$ emissions will rise sharply if the current trends (exploiting a large amount of fossil fuels) continue. Decision makers are thus forced to make efforts to reduce the carbon intensity by replacing fossil fuels with non- $\mathrm{CO}_{2}$-emission sources (e.g. hydroelectric plants, wind power, and solar power). However, decision makers are unaware of the occurrences of $\mathrm{CO}_{2}$-reduction levels under uncertain electricity demand over a long-term planning horizon. 


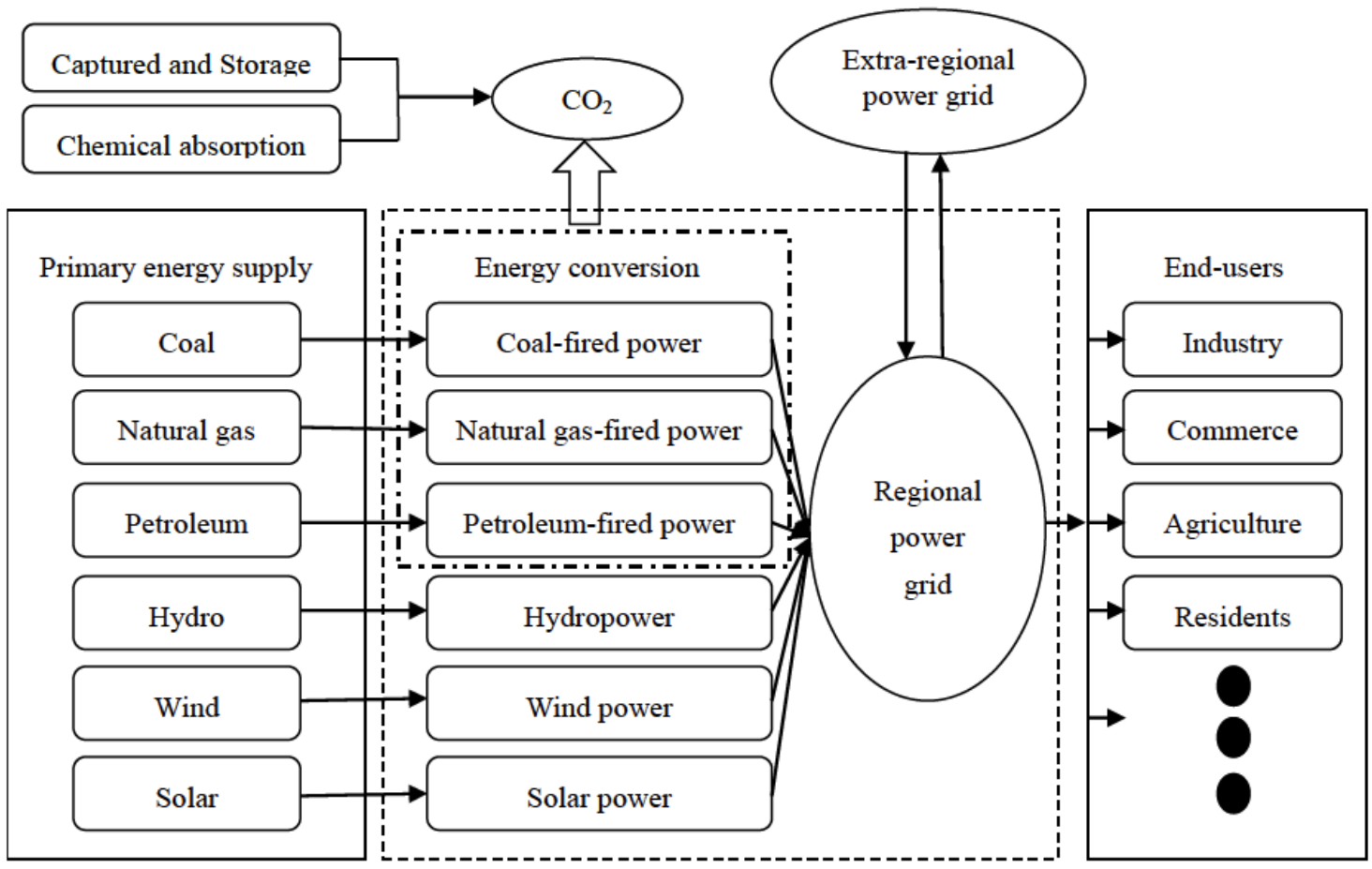

Figure 1: The schematic of regional electric-power system.

Table 1: End-User's Total Electricity Demands and Electricity Generation Targets

\begin{tabular}{|c|c|c|c|c|c|c|}
\hline Time Period & \multicolumn{2}{|c|}{$t=1$} & \multicolumn{2}{|c|}{$t=2$} & \multicolumn{2}{|c|}{$t=3$} \\
\hline \multicolumn{7}{|c|}{ End-User's Total Electricity Demand $\left(10^{3} \mathrm{GWh}\right)$} \\
\hline Demand Level & $\begin{array}{c}\text { Probability } \\
(\%)\end{array}$ & $\begin{array}{l}\text { Electricity } \\
\text { Demand }\end{array}$ & $\begin{array}{c}\text { Probability } \\
\text { (\%) }\end{array}$ & $\begin{array}{l}\text { Electricity } \\
\text { Demand }\end{array}$ & $\begin{array}{l}\text { Probability } \\
\text { (\%) }\end{array}$ & $\begin{array}{c}\text { Electricity } \\
\text { Demand }\end{array}$ \\
\hline Low $(L)$ & 25 & {$[50,65]$} & 20 & {$[85,105]$} & 15 & {$[135,150]$} \\
\hline Medium (M) & 50 & {$[65,81]$} & 60 & {$[105,127]$} & 55 & {$[150,175]$} \\
\hline High $(H)$ & 25 & {$[81,96]$} & 20 & {$[127,147]$} & 30 & {$[175,200]$} \\
\hline \multicolumn{7}{|c|}{ Electricity generation targets of each power conversion technology $\left(10^{3} \mathrm{GWh}\right)$} \\
\hline Coal-fired power & \multicolumn{2}{|c|}{$[27.5,50.0]$} & \multicolumn{2}{|c|}{$[25.0,60.0]$} & \multicolumn{2}{|c|}{$[22.5,70.0]$} \\
\hline Gas-fired power & \multicolumn{2}{|c|}{$[6.0,20.0]$} & \multicolumn{2}{|c|}{$[7.0,25.0]$} & \multicolumn{2}{|c|}{$[8.0,30.0]$} \\
\hline Petroleum-fired power & \multicolumn{2}{|c|}{$[0.5,8.0]$} & \multicolumn{2}{|c|}{$[0.75,8.5]$} & \multicolumn{2}{|c|}{$[1.0,9.5]$} \\
\hline Hydropower & \multicolumn{2}{|c|}{$[5.0,10.0]$} & \multicolumn{2}{|c|}{$[5.5,15.0]$} & \multicolumn{2}{|c|}{$[6.0,20.0]$} \\
\hline Wind power & \multicolumn{2}{|c|}{$[0,5.0]$} & \multicolumn{2}{|c|}{$[0,5.0]$} & \multicolumn{2}{|c|}{$[0,5.0]$} \\
\hline Solar power & \multicolumn{2}{|c|}{$[0,5.0]$} & \multicolumn{2}{|c|}{$[0,5.0]$} & \multicolumn{2}{|c|}{$[0,5.0]$} \\
\hline
\end{tabular}

Based on the regional environmental protection policy, the gross of $\mathrm{CO}_{2}$ emissions are interpreted as constraints in the developed model. Correspondingly, different environmental management policies may lead to varied power generation plans and changed capacity expansion schemes. In this study, three different cases are considered in order to make in-depth analysis of interactions among energy-supply security, economic cost, and environmental requirement. These cases can be described as follow:
- $\quad$ Case 1 is based on current status of the regional electric-power system without any particular regulatory, economic or political barriers, targets or strategies. Under this case, the developed model is run without any exterior constraints (e.g. without $\mathrm{CO}_{2}$ emission control constraints). Given a range of energy resources and technology alternatives, it will automatically choose the lowest-cost set of options to meet the random electricity demand in the region. 
Table 2: Economic and Technological Datum of Each Power Conversion Technology

\begin{tabular}{|c|c|c|c|c|}
\hline \multicolumn{2}{|c|}{ Conversion technology } & \multicolumn{3}{|c|}{ Time Period } \\
\hline \multicolumn{5}{|c|}{ Regular and surplus costs for power generation by each power conversion technology ( $\left.\$ 10^{3} / \mathrm{GWh}\right)$} \\
\hline \multirow{2}{*}{ Coal-fired power } & Regular cost & {$[6.5,7.0]$} & {$[7.0,7.5]$} & {$[7.5,8.0]$} \\
\hline & Surplus cost & {$[4.0,5.0]$} & {$[4.5,5.5]$} & {$[5.0,6.0]$} \\
\hline \multirow{2}{*}{ Petroleum-fired power } & Regular cost & {$[5.5,6.0]$} & {$[6.0,6.5]$} & {$[6.5,7.0]$} \\
\hline & Surplus cost & {$[3.0,4.0]$} & {$[3.5,4.5]$} & {$[4.0,5.0]$} \\
\hline \multirow{2}{*}{ Hydropower } & Regular cost & {$[5.0,6.0]$} & {$[5.5,6.5]$} & {$[6.0,7.0]$} \\
\hline & Surplus cost & {$[4.5,5.5]$} & {$[5.0,6.0]$} & {$[5.5,6.5]$} \\
\hline \multirow{2}{*}{ Solar power } & Regular cost & {$[2.0,3.0]$} & {$[2.5,3.5]$} & {$[2.7,4.0]$} \\
\hline & Surplus cost & {$[1.0,2.0]$} & {$[1.5,2.5]$} & {$[2.0,3.0]$} \\
\hline \multicolumn{5}{|c|}{ Fixed $\left(\$ 10^{6}\right)$ and variable $\left(\$ 10^{6} / \mathrm{GW}\right)$ costs for capacity expansion } \\
\hline \multirow{2}{*}{ Coal-fired power } & Fixed cost & {$[385,395]$} & {$[445,455]$} & {$[505,515]$} \\
\hline & Variable cost & {$[825,850]$} & {$[875,900]$} & {$[925,950]$} \\
\hline \multirow{2}{*}{ Gas-fired power } & Fixed cost & {$[350,375]$} & {$[405,425]$} & {$[455,475]$} \\
\hline & Variable cost & {$[785,800]$} & {$[835,850]$} & {$[885,900]$} \\
\hline Petroleum-fired power & Fixed cost & {$[310,335]$} & {$[370,395]$} & {$[415,435]$} \\
\hline Solar power & Variable cost & {$[2350,2400]$} & {$[2450,2500]$} & {$[2550,2600]$} \\
\hline \multicolumn{5}{|c|}{ Variable upper bounds for capacity expansion of each power conversion technology (GW) } \\
\hline \multicolumn{2}{|c|}{ Coal-fired power } & 0.7 & 0.5 & 0.3 \\
\hline \multicolumn{2}{|c|}{ Gas-fired power } & 0.5 & 0.6 & 0.7 \\
\hline \multicolumn{2}{|c|}{ Petroleum-fired power } & 0.45 & 0.5 & 0.6 \\
\hline \multicolumn{2}{|c|}{ Hydropower } & 0.3 & 0.4 & 0.5 \\
\hline \multicolumn{2}{|c|}{ Wind power } & 0.1 & 0.2 & 0.3 \\
\hline \multicolumn{2}{|c|}{ Solar power } & 0.2 & 0.3 & 0.4 \\
\hline
\end{tabular}

In Case 2, the totaling amount of $\mathrm{CO}_{2}$ emitted are to be mitigated by $30 \%$ based on case 1 over the planning horizon. Therefore, this case corresponds to decisions with efforts for allocation and management of energy resources, services, activities and investment under stabilized environmental management policies.
Case 3 provides an analysis of varied environmental management policies for $\mathrm{CO}_{2}$ emissions allowances under an aggressive environmental protection goal over the planning horizon. Based on case 1, the gross of region's $\mathrm{CO}_{2}$ emissions are to be mitigated by $50 \%$ along with the time period. 


\subsection{Modeling Formulation}

Based on the ITSIP method, the objective is to minimize the system cost under consideration of generating desired energy resources allocation, import electricity quantities, capacity expansion plans and $\mathrm{CO}_{2}$ emissions management policies. The system cost includes expense for energy resources supply, cost for import electricity, operating cost, and capacity expansion cost for power conversion technologies, operating cost for $\mathrm{CO}_{2}$ control techniques, and economic penalty as corrective measures or recourse cost against any infeasibilities arising due to a particular realization of an uncertain event. Therefore, the study problem can be formulated as follows:

$\operatorname{Min} f^{ \pm}=(a)+(b)+(c)+(d)$

(a) Purchase costs for coal, natural gas, petroleum and imported electricity:

$\sum_{t=1}^{T}\left(P E C_{t}^{ \pm} Z 1_{t}^{ \pm}+P E N_{t}^{ \pm} Z 2_{t}^{ \pm}+P E O_{t}^{ \pm} Z 3_{t}^{ \pm}\right)+\sum_{t=1}^{T} \sum_{h=1}^{H_{t}} p_{t h} P I E_{t}^{ \pm} Z 4_{t h}^{ \pm}$

(b) Operating costs for electricity conversion:

$$
\sum_{i=1}^{I} \sum_{t=1}^{T} P V_{i t}^{ \pm} W_{i t}^{ \pm}+\sum_{i=1}^{I} \sum_{t=1}^{T} \sum_{h=1}^{H_{t}} p_{t h}\left(P V_{i t}^{ \pm}+P P_{i t}^{ \pm}\right) Q_{i t h}^{ \pm}
$$

(C) Capital costs for capacity expansions of electricity conversion technologies:

$\sum_{i=1}^{I} \sum_{t=1}^{T} \sum_{h=1}^{H_{t}} p_{t h}\left(A_{i t}^{ \pm} Y_{i t h}^{ \pm}+B_{i t}^{ \pm} X_{i t h}^{ \pm}\right)$

(d) Operating costs for $\mathrm{CO}_{2}$ emission control:

$$
\sum_{i=1}^{I} \sum_{j_{c}=1}^{n_{c}} \sum_{t=1}^{T} C C_{j_{c} t}^{ \pm} X C_{i_{c} t}^{ \pm}+\sum_{i=1}^{I} \sum_{j_{c}=1}^{n_{c}} \sum_{t=1}^{T} \sum_{h=1}^{H_{t}} p_{t h} D C_{j_{c} t}^{ \pm} Y C_{i_{c} t h}^{ \pm}
$$

Meanwhile, the total system cost should be minimized subject to a set of constraints that describe various impact factors and their interactions. The constraints can be formulated as follows:

(1) Constraints for mass balance: These constraints describe the balance of energy flows in the study system. They are established to ensure that the input energy is greater than the output one.

$$
\begin{aligned}
& \left(W_{1 t}^{ \pm}+Q_{1 t h}^{ \pm}\right) F E_{1 t}^{ \pm} \leq Z 1_{t}^{ \pm}, \forall t ; h=1, \ldots, H_{t} \\
& \left(W_{2 t}^{ \pm}+Q_{2 t h}^{ \pm}\right) F E_{2 t}^{ \pm} \leq Z 2_{t}^{ \pm}, \forall t ; h=1, \ldots, H_{t}
\end{aligned}
$$

$$
\left(W_{3 t}^{ \pm}+Q_{3 t h}^{ \pm}\right) F E_{3 t}^{ \pm} \leq Z 3_{t}^{ \pm}, \forall t ; h=1, \ldots, H_{t}
$$

(2) Constraints for availabilities of energy resources: These constraints identify energy resource availabilities. There are limited renewable energy resources, which imply necessity for effective use of them. When local available resources cannot meet demand, importing electricity from other regions at high purchase costs will become necessary.

$$
\begin{aligned}
& \left(W_{4 t}^{ \pm}+Q_{4 t h}^{ \pm}\right) F E_{4 t}^{ \pm} \leq U P H_{t}^{ \pm}, \forall t ; h=1, \ldots, H_{t} \\
& \left(W_{5 t}^{ \pm}+Q_{5 t h}^{ \pm}\right) F E_{5 t}^{ \pm} \leq U P W_{t}^{ \pm}, \forall t ; h=1, \ldots, H_{t} \\
& \left(W_{6 t}^{ \pm}+Q_{6 t h}^{ \pm}\right) F E_{6 t}^{ \pm} \leq U P S_{t}^{ \pm}, \forall t ; h=1, \ldots, H_{t}
\end{aligned}
$$

(3) Constraints for electricity supply and demand balance: These constraints are established to ensure that the electricity generated from various energy resources is not less than the amount of demand specified by the end users. Electricity demand is presented by random intervals with a given probability.

$$
\begin{aligned}
& \sum_{i=1}^{I}\left(W_{i t}^{ \pm}+Q_{i t h}^{ \pm}+Z 4_{t h}^{ \pm}\right) \geq d_{t h}^{ \pm}, \forall t ; h=1, \ldots, H_{t} \\
& W_{i t}^{ \pm}+Q_{i t h}^{ \pm} \leq\left(R C_{i}+\sum_{i=1}^{t} X_{i t h}^{ \pm}\right) S T_{i t}^{ \pm}, \forall i, t ; h=1, \ldots, H_{t} \\
& W_{i t}^{ \pm} \geq Q_{i t h}^{ \pm} \geq 0, \forall i, t ; h=1, \ldots, H_{t}
\end{aligned}
$$

(4) Constraints for electricity load demand: These constraints regulate the existing and future expanding capacities have to satisfy the local electricity load demand.

$$
\sum_{i=1}^{I}\left(R C_{i}+\sum_{i=1}^{t} X_{i t h}^{ \pm}\right) \geq V_{t}^{ \pm}, \forall t ; h=1, \ldots, H_{t}
$$

(5) Constraints for capacity expansion of electricitygeneration facilities: If electricity supply cannot sufficiently meet increasing demand from end-users, decision-makers have to face a dilemma of either investing more funds on capacity expansion of existing facilities or turning to other energy production options with higher costs. Integer programming technique is used to facilitate dynamic analysis, such as timing, sizing and siting decisions in capacity-expansion schemes for electricity-generation facilities [5].

$$
\begin{aligned}
& Y_{i t h}^{ \pm}\left\{\begin{array}{l}
=1, \text { if capacity expansion is undertaken } \\
=0, \text { if otherwise }
\end{array}, \forall i, t ; h=1, \ldots, H_{t}\right. \\
& N_{i t} \leq X_{i t h}^{ \pm} \leq M_{i t} Y_{i t h}^{ \pm}, \forall i, t ; h=1, \ldots, H_{t}
\end{aligned}
$$


(6) Constraints for $\mathrm{CO}_{2}$ control demand: These constraints assure that the amount of $\mathrm{CO}_{2}$ be mitigated by control measure $j_{c}$ in period $t$ must exceed actual emissions.

$$
\begin{aligned}
& W_{i t}^{ \pm} I N C_{i t}^{ \pm} \leq \sum_{j_{c}}^{n_{c}} X C_{i j_{c}}^{ \pm}, \forall i ; t \\
& Q_{i t h}^{ \pm} I N C_{i t}^{ \pm} \leq \sum_{j_{c}}^{n_{c}} Y C_{i j_{c} t h}^{ \pm}, \forall i ; t ; h=1, \ldots, H_{t}
\end{aligned}
$$

(7) Constraints for $\mathrm{CO}_{2}$ emission allowance: These constraints require the cumulative $\mathrm{CO}_{2}$ emissions over the planning horizon must not exceed specified amount.

$$
\sum_{i=1}^{I} \sum_{j_{c}=1}^{n_{c}}\left(1-\eta_{j_{c}}^{ \pm}\right)\left(X C_{i_{j_{c}} t}^{ \pm}+Y C_{i_{j_{c}} t h}^{ \pm}\right) \leq E C_{t}^{ \pm}, \forall t ; h=1, \ldots, H_{t}
$$

(8) Non-negativity constraints: These constraints assure that only positive electricity-conversion activities are considered in the solution.

$$
\begin{aligned}
& Z 1_{t}^{ \pm}, Z 2_{t}^{ \pm}, Z 3_{t}^{ \pm}, Z 4_{t h}^{ \pm}, W_{i t}^{ \pm}, Q_{i t h}^{ \pm}, X C_{i_{j} t}^{ \pm}, Y C_{i_{c} t h}^{ \pm} \geq 0, \\
& \forall i ; j_{c} ; t ; h=1, \ldots, H_{t}
\end{aligned}
$$

The detailed nomenclatures for the variables and parameters are provided in Appendix A. Solution procedure of the proposed model is provided in Appendix B.

\section{RESULT ANALYSIS}

\subsection{Energy Resources Supply Scheme}

Figures 2 and $\mathbf{3}$ show the energy resources supply schemes under cases 1, 2 and 3 . In this study, coal, natural gas and petroleum would be supplied based on the results of the worst scenario (i.e. related to a maximum electricity deficit level); this is to guarantee the security of energy supplies under uncertainty. Under case 1, as shown in the Figure $\mathbf{2 a}$, the amount of coal supply would significantly increase, being [390.0., 487.50], [579.15, 725.40] and [496.86, 663.59] $\times 10^{3} \mathrm{TJ}$ in periods 1,2 and 3 , respectively. Coal would play the most important role in the energy supply activities under this case. This is due to the following two facts: (i) there are no $\mathrm{CO}_{2}$ emission control constraints under this case; (ii) coal-fired power conversion technology has the lowest operating and penalty cost of all the power conversion technologies. Natural gas supply would be [75.24, 96.14], [277.32, $355.22]$ and $[307.65,426.24] \times 10^{3} \mathrm{TJ}$ in periods 1,2 and 3 , respectively. Petroleum supply would be [83.54, 103.20], [148.38, 183.70] and $[217.88,293.55] \times 10^{3} \mathrm{TJ}$ in periods 1,2 and 3 , respectively. In addition, for the imported electricity, as shown in the Figure $\mathbf{3 a}$, the amount would be varied according to the electricity demand-levels in each period.

Compared with the results under case 1 , as shown in the Figure $\mathbf{2 b}$, the amount of coal supply would almost be stabilized at a certain level over the planning horizon. This is because the total amount of $\mathrm{CO}_{2}$ emitted would be confined with a certain level during the planning periods, while coal-fired power conversion technology corresponds to a higher air pollutionemission rate, compared with other power conversion technologies. In comparison, the amount of natural gas supply would be raised with the increasing electricity demand. This is because capacities of gas-fired power would be expanded to meet the random electricity demands in these periods. The amount of petroleum supply would decrease in period 1, but increase in period 2. For the imported electricity, as shown in the Figure $\mathbf{3 b}$, there would also be decrease in periods 1 and 2 . Under case 3 , the role of coal supply would be ever decreasing in the energy supply activities compared with the results under cases 1 and 2 as shown in Figure 2c. This is because, under this case, strict environmental policies for $\mathrm{CO}_{2}$ emissions management would be adopted.

\subsection{Electricity Generation Plan}

Figure 4 present the optimized electricity generation plans of every power conversion technology under the three cases. Under case 1, coal-fired power would play the most important part in the electricity generation activities, whose optimized generation targets would be $39.50,29.25$ and $50.70 \times 10^{3} \mathrm{GWh}$ in periods 1,2 and 3 , respectively. For the gas-fired power, its optimized generation targets would be 14.18, 15.58 and $28.96 \times 10^{3} \mathrm{GWh}$ in the three planning periods, respectively, which would nearly reach its upper target level in periods 2 and 3 (as shown in Table 1). For petroleum-fired power, its optimized generation targets would be $4.91,8.33$ and $9.25 \times 10^{3} \mathrm{GWh}$ in the three planning periods, respectively. For the hydropower, its optimized generation targets would increase in period 3 , being $14.95 \times 10^{3} \mathrm{GWh}$. The optimized generation targets of the wind and solar power would be 0,0 , $3.00 \times 10^{3} \mathrm{GWh}$ and $0,0,4.14 \times 10^{3} \mathrm{GWh}$ in periods 1,2 and 3 , respectively. Under case 2 , as constraints for 

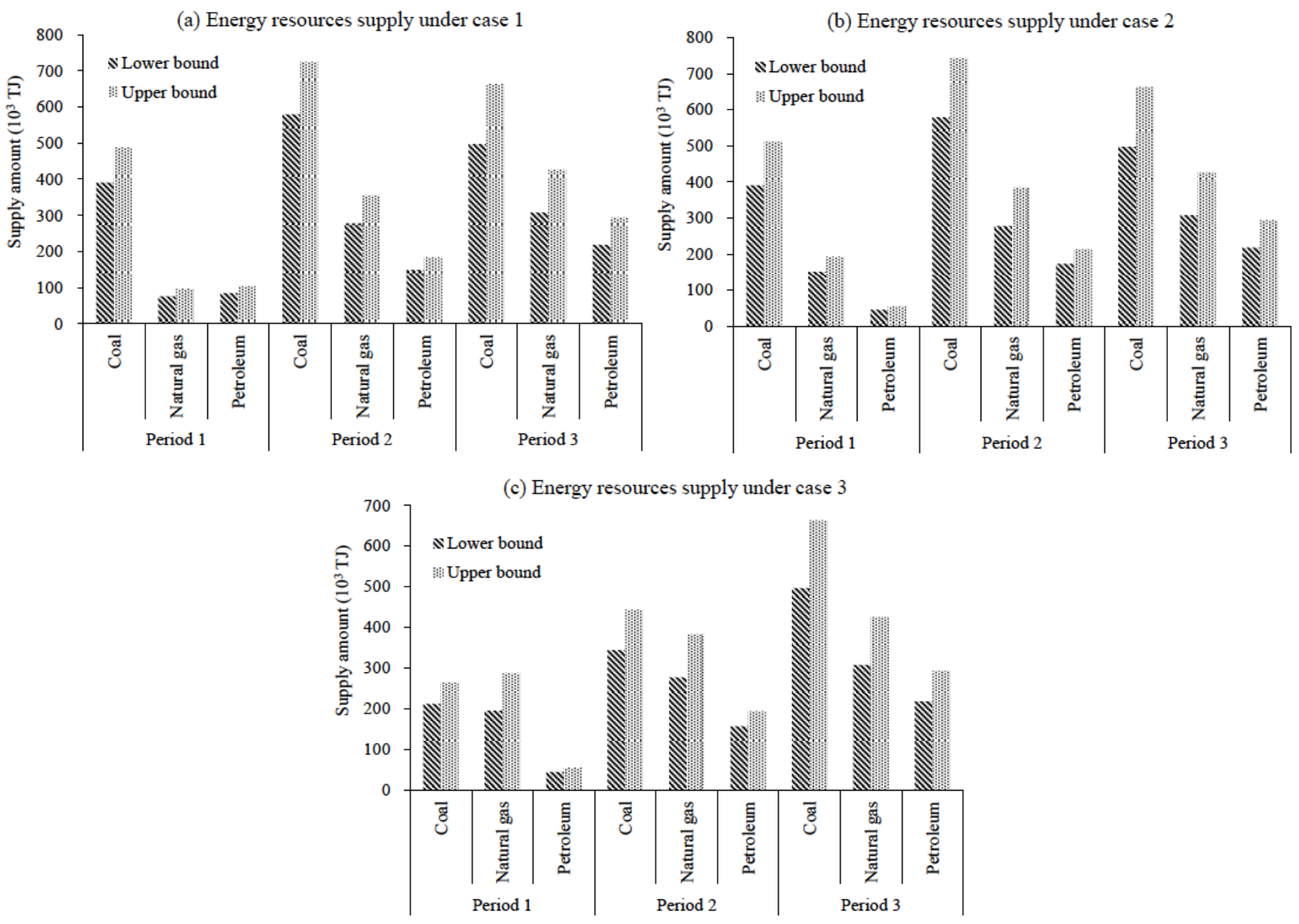

Figure 2: Coal, natural gas and petroleum supply under cases 1, 2 and 3 .
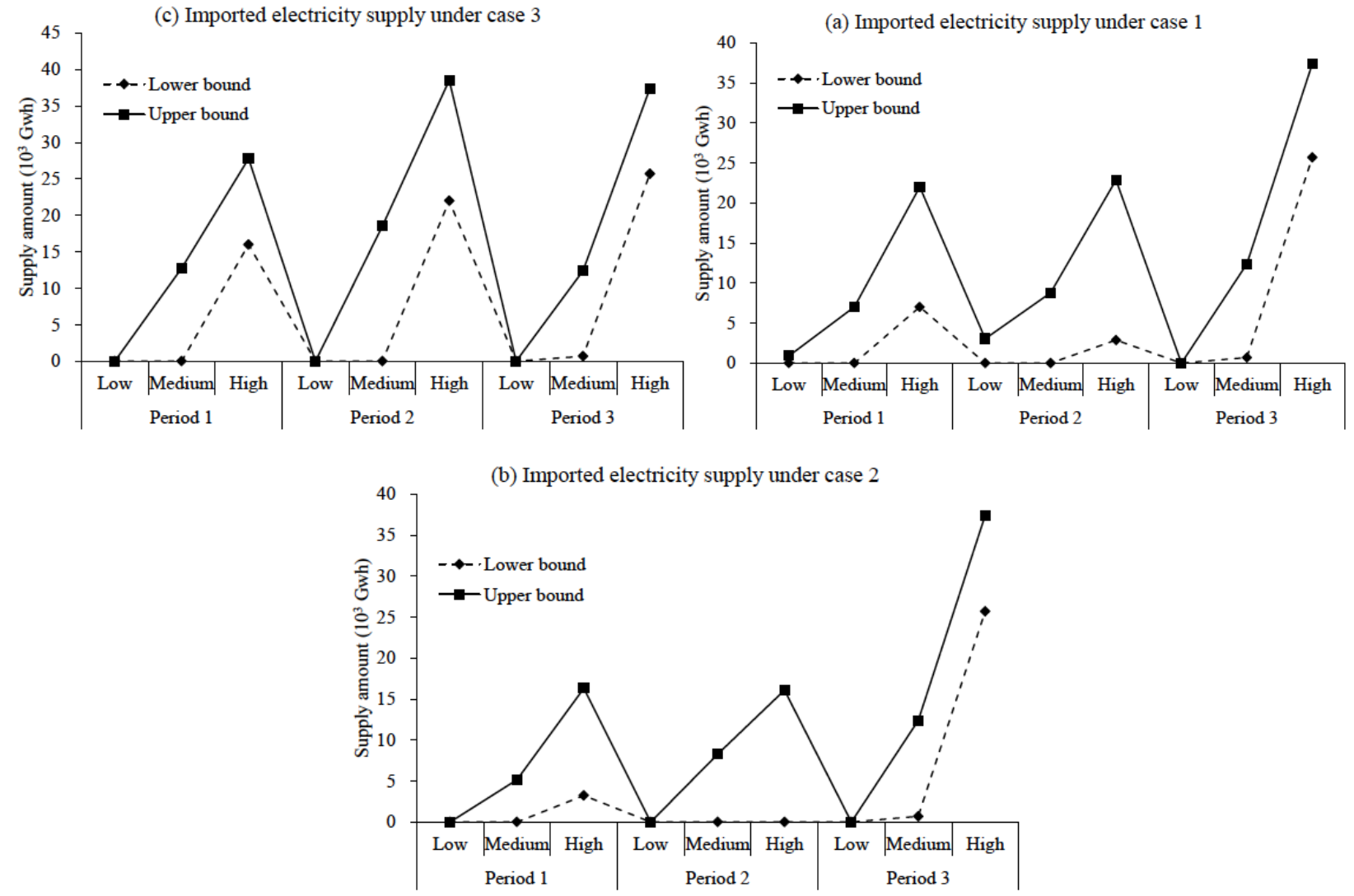

Figure 3: Imported electricity supply under cases 1, 2 and 3. 

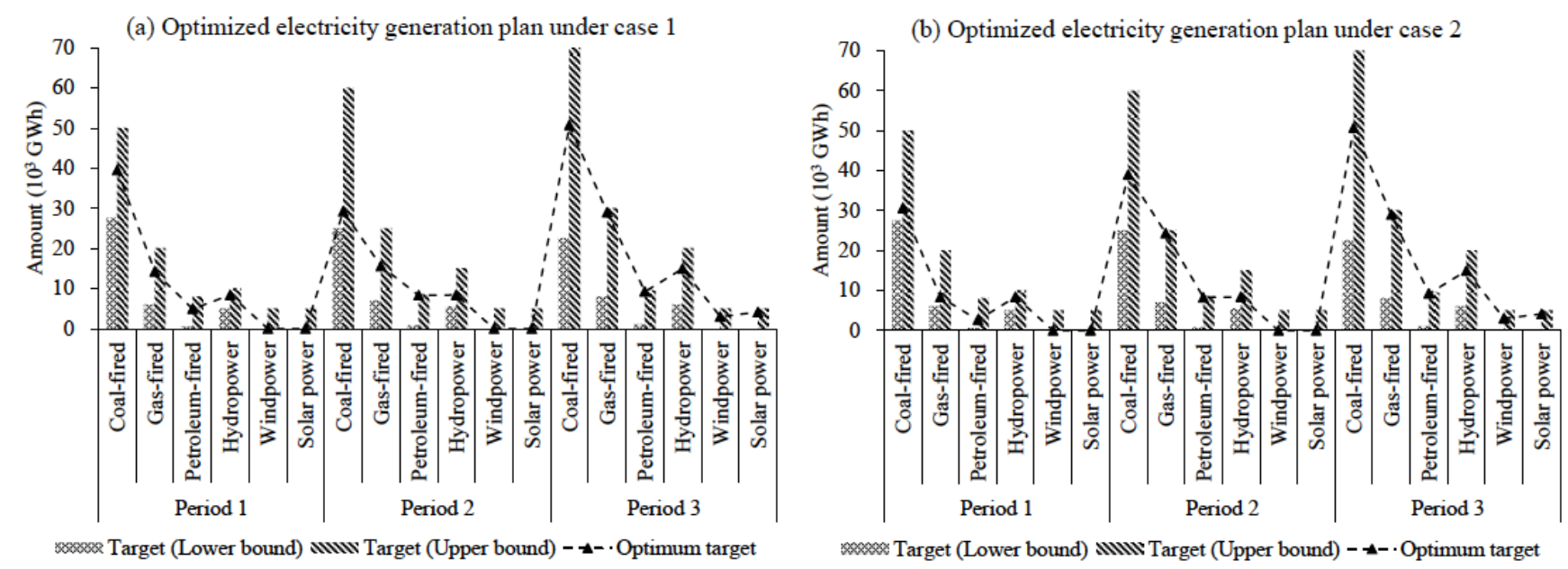

(c) Optimized electricity generation plan under case 3

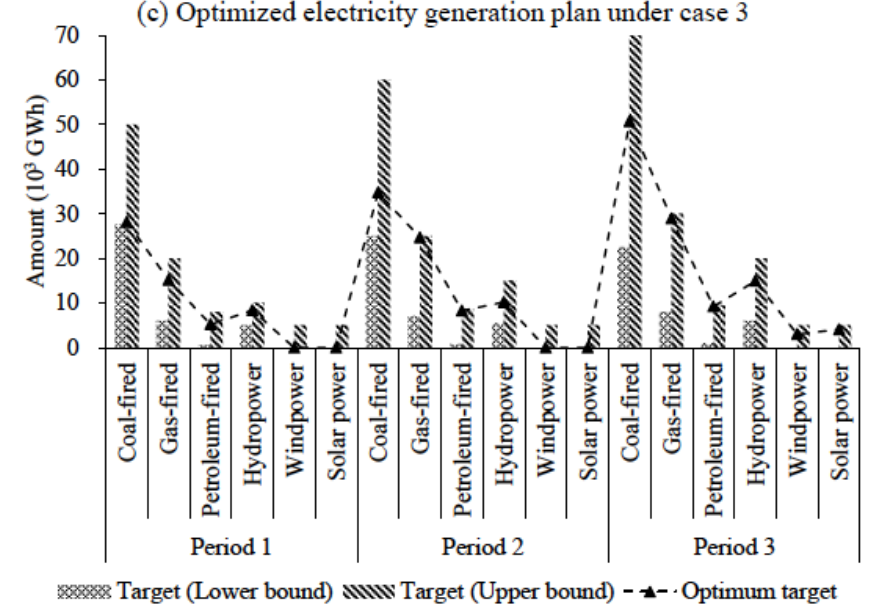

Figure 4: Optimized electricity generation plans for each power conversion technology under cases 1, 2 and 3.

gross control of $\mathrm{CO}_{2}$ emission are added, generation quantity of coal-fired power would not significantly increase, due to its high $\mathrm{CO}_{2}$-emission rates. Meanwhile, generation quantities of gas-fired power and hydropower would markedly increase and clean power conversion technologies (associated with low $\mathrm{CO}_{2}$-emission rates) would be adopted. Under case 3 , as more strict environmental protection objectives must be achieved than those under cases 1 and 2, the dominant role of coal-fired power would completely be replaced by other conversion technologies.

Deficits would occur if the available generation targets cannot meet the random electricity demand, especially when the demand-level is high. In general, different power conversion technology has varied excess generation quantities under changed possible scenarios. For example, under case 3 , the excess generation quantities would be $[0,3.25] \times 10^{3} \mathrm{GWhfor}$ the coal-fired power, $[0,2.76] \times 10^{3} \mathrm{GWh}$ for the gasfired power, $[0,2.25] \times 10^{3} \mathrm{GWh}$ for the petroleum-fired power, $[8.45,12.35] \times 10^{3} \mathrm{GWh}$ for the hydropower, 3.00 $\times 10^{3} \mathrm{GWh}$ for the solar power and $[2.86,4.00] \times 10^{3} \mathrm{GWh}$ for the solar power when the demand-level is high in period 1 (probability is $25 \%$ ).

\subsection{Capacity Expansion}

Table 3 displays the solutions of capacity expansion schemes of each conversion technology under the three cases. Generally, shortages would occur if the electricity demand-levels are continuously high, and a capacity expansion project would be undertaken to avoid insufficient electricity supply. For example, under case 3 , there would be $[0,0.65] \mathrm{GW}$ for coal-fired power conversion technology to be expanded when the electricity demand-level is low (probability is $25 \%$ ) in period 1. When the demand-level is medium (probability is $50 \%$ ) and high (probability is $25 \%$ ) in period 1, the amount of expansion would all be $[0,0.57]$ GW. For hydropower, the amount of expansion would all be [0,0.20], 0.28 and 0.28 when the demand-level is low, medium and high, respectively. For wind power and solar power, there would be no capacity expansion 
Table 3: Capacity Expansion Schemes under Cases 1, 2 and 3

\begin{tabular}{|c|c|c|c|c|c|c|c|c|c|c|}
\hline \multirow{2}{*}{$\begin{array}{l}\text { Conversion } \\
\text { Technology }\end{array}$} & \multirow{2}{*}{ Period } & \multicolumn{9}{|c|}{ Expansion Amount (GW) under Varied Electricity Demand-Level } \\
\hline & & Case 1 & Case 2 & Case 3 & Case 1 & Case 2 & Case 3 & Case 1 & Case 2 & Case 3 \\
\hline \multirow[b]{2}{*}{$\begin{array}{l}\text { Coal-fired } \\
\text { power }\end{array}$} & $t=1$ & {$[0,0.70]$} & {$[0,0.40]$} & {$[0,0.65]$} & {$[0,0.70]$} & {$[0,0.65]$} & {$[0,0.57]$} & {$[0,0.62]$} & {$[0,0.57]$} & {$[0,0.57]$} \\
\hline & $t=2$ & $\begin{array}{l}{[0.34} \\
0.50]\end{array}$ & {$[0,0.50]$} & {$[0,0.45]$} & $\begin{array}{l}{[0.23} \\
0.50]\end{array}$ & $\begin{array}{l}{[0.15,} \\
0.50]\end{array}$ & {$[0,0.35]$} & 0.50 & 0.50 & {$[0,0.35]$} \\
\hline \multirow{3}{*}{$\begin{array}{c}\text { Gas-fired } \\
\text { power }\end{array}$} & $t=1$ & 0 & {$[0,0.50]$} & $\begin{array}{l}{[0.18} \\
0.50]\end{array}$ & 0 & $\begin{array}{r}{[0.22} \\
0.50]\end{array}$ & $\begin{array}{l}{[0.35} \\
0.50]\end{array}$ & 0 & $\begin{array}{l}{[0.22} \\
0.50]\end{array}$ & $\begin{array}{l}{[0.35} \\
0.50]\end{array}$ \\
\hline & $t=2$ & $\begin{array}{l}{[0.19} \\
0.60]\end{array}$ & $\begin{array}{l}{[0.50} \\
0.60]\end{array}$ & $\begin{array}{l}{[0.59} \\
0.60]\end{array}$ & 0.60 & 0.60 & 0.60 & 0.60 & 0.60 & 0.60 \\
\hline & $t=3$ & 0.70 & 0.70 & 0.70 & 0.70 & 0.70 & 0.70 & 0.70 & 0.70 & 0.70 \\
\hline $\begin{array}{l}\text { Petroleum- } \\
\text { fired power }\end{array}$ & $t=3$ & 0.60 & 0.60 & 0.60 & 0.60 & 0.60 & 0.60 & 0.60 & 0.60 & 0.60 \\
\hline \multirow{3}{*}{ Hydropower } & $t=1$ & {$[0,0.20]$} & 0 & {$[0,0.20]$} & {$[0,0.20]$} & {$[0,0.20]$} & 0.28 & 0.28 & 0.28 & 0.28 \\
\hline & $t=2$ & {$[0,0.25]$} & {$[0,0.25]$} & $\begin{array}{l}{[0.06} \\
0.30]\end{array}$ & {$[0,0.25]$} & {$[0,0.25]$} & 0.40 & 0.28 & 0.28 & 0.40 \\
\hline & $t=3$ & $\begin{array}{l}{[0.22} \\
0.34]\end{array}$ & $\begin{array}{l}{[0.22} \\
0.37]\end{array}$ & $\begin{array}{r}{[0.22} \\
0.37]\end{array}$ & 0.50 & 0.50 & 0.50 & 0.50 & 0.50 & 0.50 \\
\hline \multirow[b]{2}{*}{ Wind power } & $t=1$ & 0 & 0 & 0 & 0 & 0 & 0 & 0 & 0 & 0 \\
\hline & $t=2$ & 0 & 0 & 0 & 0 & 0 & 0 & 0 & 0 & 0 \\
\hline
\end{tabular}

in periods 1 and 2. $0.15,0.30$ and $0.30 \mathrm{GW}$ would be expanded for wind power when the demand-level is low (probability is $15 \%$ ), medium (probability is $55 \%$ ) and high (probability is $30 \%$ ) in period 3 , respectively. 0.26 , 0.40 and $0.40 \mathrm{GW}$ would be expanded for solar power when the demand-level is low, medium and high in period 3 , respectively.

\section{4. $\mathrm{CO}_{2}$ Emissions Control}

In this study, a project of air-pollution control was considered, in order to satisfy the ambient air quality requirement and to reduce the penalty towards excess emission. Figure 5 shows the optimized $\mathrm{CO}_{2}$ mitigation plans under the three cases. Under case 1 , the target amounts of treated $\mathrm{CO}_{2}$ would be significantly increased along with the ever increasing electricity demand-levels as shown in Figure 5a. This is attributed to the fact that the developed model is run without any exterior constraints (e.g. without $\mathrm{CO}_{2}$ emissions control constraints) under this case. There would be $[40.97$, 43.97], [27.80, 33.32] and [27.31, 33.32] $\times 10^{3}$ tonnes of $\mathrm{CO}_{2}$ mitigated by $\mathrm{CS},[0,6.01],[26.34,27.31]$ and $27.31 \times 10^{3}$ tonnes of $\mathrm{CO}_{2}$ mitigated by $\mathrm{CA}$, when the electricity demand-levels are low, medium and high (probabilities are $25 \%, 50 \%$ and $25 \%$ ) in period 1 , respectively. When the electricity demand-levels are low, medium and high (probabilities are $20 \%, 60 \%$ and $20 \%$ ) in period 2 , the amount of mitigation by CS would be $[70.88,75.12],[58.30,62.54]$ and $[47.25,55.74] \times$ $10^{3}$ tonnes, the amount of mitigation by CA would be [0, 8.48], [25.16, 33.65] and $47.25 \times 10^{3}$ tonnes, respectively.

Under case 2, when environmental constraints are added, high-efficiency mitigation measures must be installed to reduce the $\mathrm{CO}_{2}$ emissions and to satisfy the environmental requirements. Thus, the results would 
(a) $\mathrm{CO}_{2}$ mitigation plan under case 1

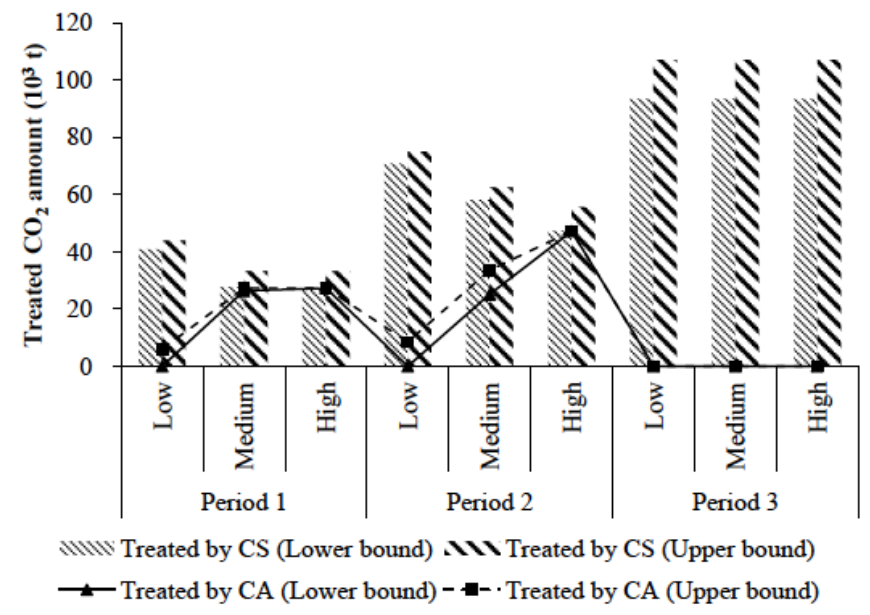

(b) $\mathrm{CO}_{2}$ mitigation plan under case 2

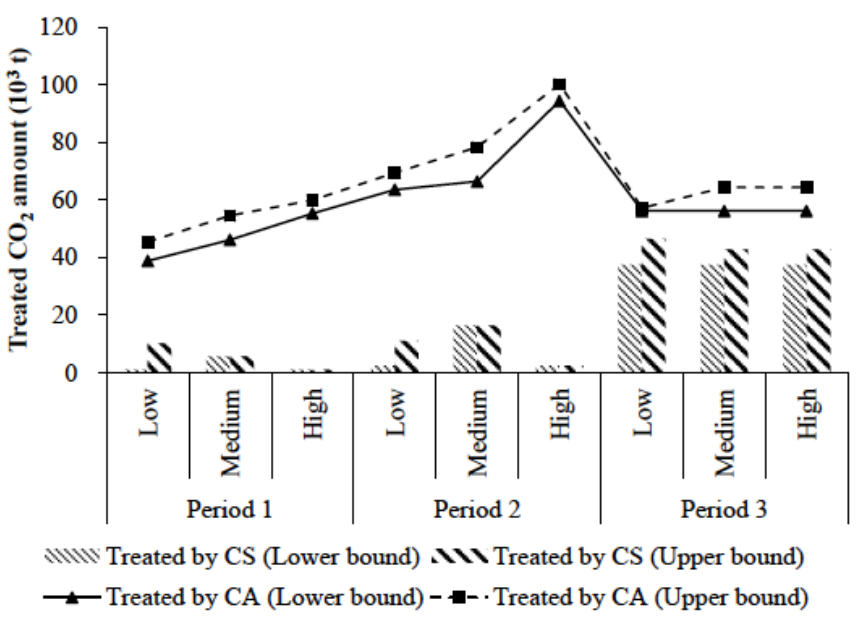

(c) $\mathrm{CO}_{2}$ mitigation plan under case 3

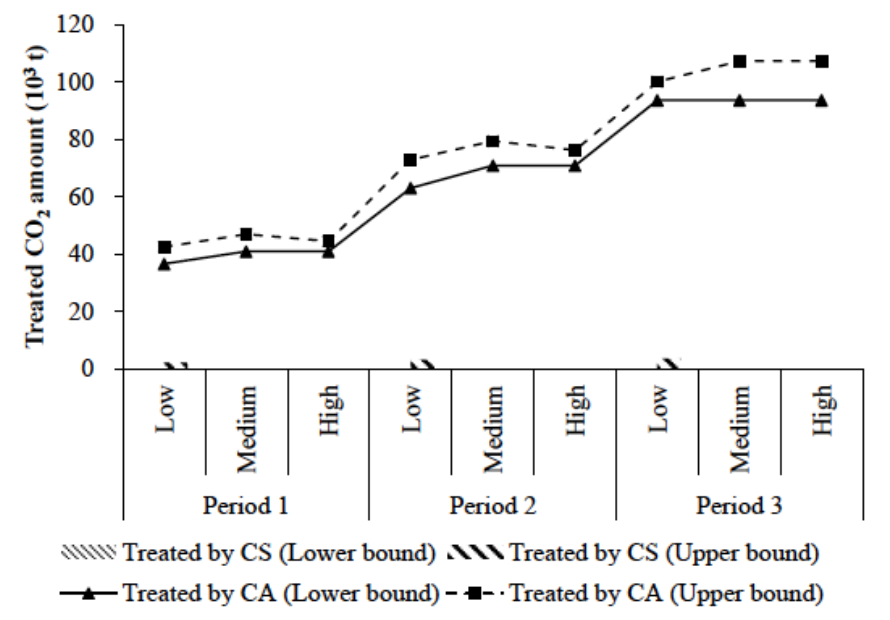

Figure 5: $\mathrm{CO}_{2}$ mitigation plans under cases 1, 2 and 3.

provide useful bases for generating decision alternatives with a desired technology combination that would lead to a satisfied environmental quality as well as a minimized abatement cost. Under case 3 , the target amounts of treated $\mathrm{CO}_{2}$ would be significantly decreased along with the time periods. This is because an aggressive environmental protection goal must be achieved under this case. Therefore, electricity generated from coal-fired, gas-fired and petroleum-fired power conversion technologies would be reduced accordingly. And thus, mitigation measures with higher efficiency must be installed to reduce the pollution emissions and to satisfy the stricter environmental requirements.

\subsection{System Cost}

The system cost includes expenses for energy resources supply, operating costs and capacity expansion costs for power conversion technologies, and operating costs for $\mathrm{CO}_{2}$ emissions control techniques. Figure 6 presents the detailed systems cost under different cases. The costs for energy resources supply are $\$[21.19,43.15] \times 10^{9}$ (or $[51.12$, $61.84] \%$ of the total system cost) under case $1, \$[20.84$, $41.42] \times 10^{9}$ (or $[48.96,59.46] \%$ of the total system cost) under case 2 , and $\$[23.74,49.82] \times 10^{9}$ (or [50.68, $63.99] \%$ of the total system cost) under case 3 . This indicates that the strict environmental policies would lead to an increased energy resources supply cost. The operating costs for power conversion are $\$[6.03,7.56]$ $\times 10^{9}$ (or $[10.83,14.55] \%$ of the total system cost) under case $1, \$[7.61,9.44] \times 10^{9}$ (or $[13.55,17.89] \%$ of the total system cost) under case $2, \$[7.46,9.09] \times 10^{9}$ (or $[11.67,15.93] \%$ of the total system cost) under case 3 . This demonstrates that the strict environmental policies would lead to reduced operating costs for power conversion. The expenses for capacity expansion of power conversion technologies are $\$[11.85,16.02] \times 10^{9}$ (or $[22.96,28.59] \%$ of the total system cost) under case $1, \$[11.87,15.89] \times 10^{9}$ (or 
Case 1

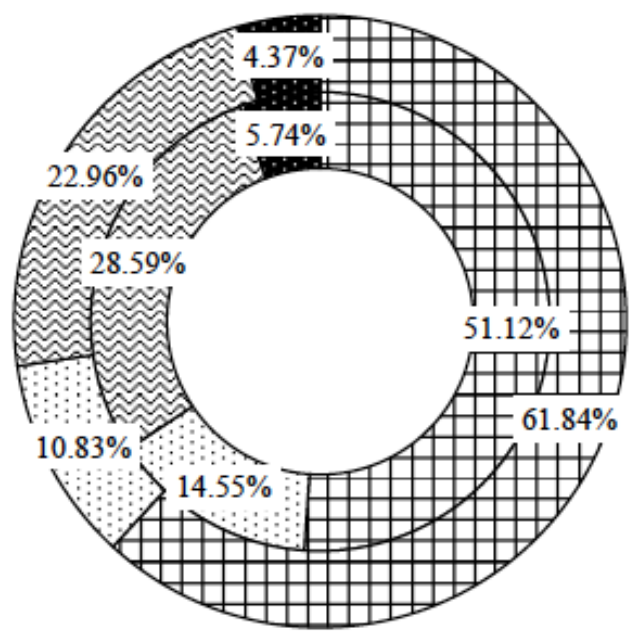

Case 2

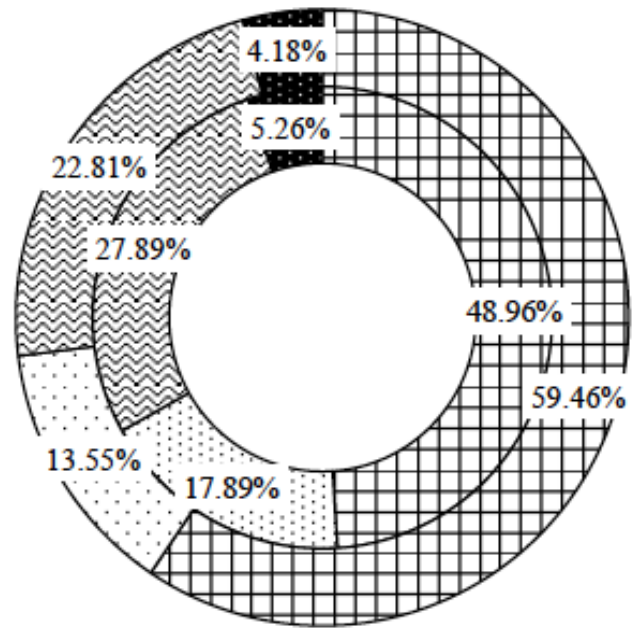

Case 3

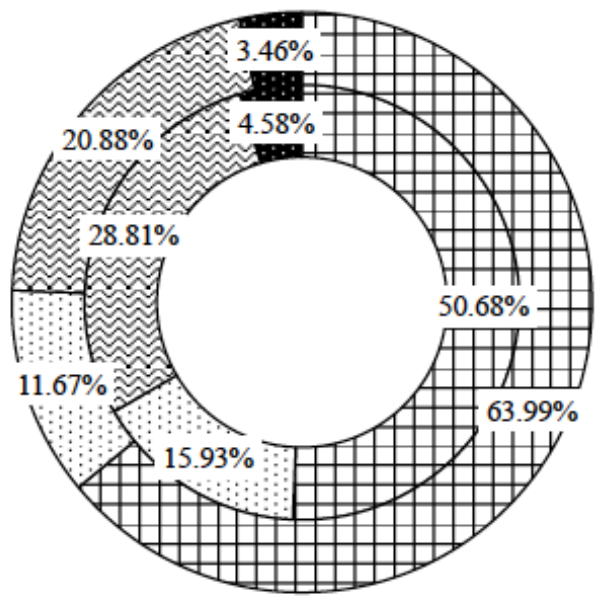

$\square$ Costs for energy resources supply

Operating cost for power conversion

$\Delta$ Cost for capacity expansion

- Operation cost for emissions control

Figure 6: Detailed system cost under cases 1, 2 and 3.

[22.81, 27.89] \% of the total system cost) under case 2 , and $\$[13.50,16.25] \times 10^{9}$ (or $[20.88,28.81] \%$ of the total system cost) under case 3 . This is due to more power conversion technologies with high price but low $\mathrm{CO}_{2}$ emission rates would be adopted in cases 2 and 3 compared with those in case 1 . The operating costs for $\mathrm{CO}_{2}$ emissions control techniques are $\$[2.38,3.05]$ $\times 10^{9}$ (or $[4.37,5.74] \%$ of the total system cost) under case $1, \$[2.24,2.91] \times 10^{9}$ (or $[4.18,5.26] \%$ of the total system cost) under case 2 , and $\$[2.14,2.69] \times 10^{9}$ (or $[3.46,4.58] \%$ of the total system cost) under case 3 . This implies that aggressive environmental management policies would lead to reduced operating costs for $\mathrm{CO}_{2}$ emissions control techniques. Therefore, decisions with stricter environmental constraints would lead to a higher system cost but a cleaner environment; conversely, a desire for reducing the system cost would result in increased risk of violating the environmental criteria.

\section{CONCLUSIONS}

In this study, an interval two-stage integer programming model is formulated for planning electricpower systems and managing $\mathrm{CO}_{2}$ emissions under uncertainty. The proposed model could not only reflect 
interactions among multiple energy-related activities, but also address uncertainties in multiple forms and dynamics within a multi-period, multi-facility, and multidemand-level context. It has also advantages in providing an effective linkage between the preregulated environmental policies and the associated economic implications. The $\mathrm{CO}_{2}$-emission reduction target and energy demand are both assumed to be random over a long-term planning horizon. The modeling results can be used for supporting decisions of electricity-generation schemes and capacityexpansion plans under different $\mathrm{CO}_{2}$-mitigation options and electricity-demand levels. The results suggest that, aggressive environmental management policies would lead to reduced operating costs for $\mathrm{CO}_{2}$ emissions control techniques. Therefore, decisions with stricter environmental constraints would lead to a higher system cost but a cleaner environment; conversely, a desire for reducing the system cost would result in increased risk of violating the environmental criteria.

\section{ACKNOWLEDGEMENTS}

This research was supported by the National Basic Research Program of China (2013CB430406), the National Natural Sciences Foundation (51225904) and the Fundamental Research Funds for the Central Universities (2014QN33). The authors are grateful to the editors and the anonymous referees for their insightful comments and suggestions.

\section{APPENDIX A. NOMENCLATURES FOR $C C_{j_{c}}^{ \pm}$ PARAMETERS AND VARIABLES}

\begin{tabular}{|c|c|}
\hline$f^{ \pm}$ & $\begin{array}{l}\text { Expected system cost over the planning } \\
\text { horizon }\left(\$ 10^{9}\right)\end{array}$ \\
\hline$i$ & $\begin{array}{l}\text { Type of power conversion technology, } \\
i=1,2, \ldots, I ; i=1 \text { for coal-fired power } \\
\text { conversion technology, } i=2 \text { for natural } \\
\text { gas-fired power conversion technology, } \\
i=3 \text { for petroleum-fired power } \\
\text { conversion technology, } i=4 \text { for } \\
\text { hydropower, } i=5 \text { for wind power; } i=6 \\
\text { for solar power }\end{array}$ \\
\hline$j_{c}$ & $\begin{array}{l}\text { Type of } \mathrm{CO}_{2} \text { control measure, } \\
j_{c}=1,2, \ldots, n_{c} ; \quad j_{c}=1 \text { for capture and } \\
\text { storage (CS); } j_{c}=2 \text { for chemical } \\
\text { absorption (CA) }\end{array}$ \\
\hline$t$ & Time period, $t=1,2, \ldots, T$ \\
\hline
\end{tabular}

Electricity demand-level, $h=1,2, \ldots, H_{t}$

\section{Parameters}

$p_{t h} \quad$ Probability of demand level $h$ occurrence in period $t(\%)$

$P E C_{t}^{ \pm} \quad$ Cost for coal supply in period $t\left(\$ 10^{3} / \mathrm{TJ}\right)$

$P E N_{t}^{ \pm} \quad$ Cost for natural gas supply in period $t$ $\left(\$ 10^{3} / \mathrm{TJ}\right)$

$\mathrm{PEO}_{t}^{ \pm} \quad$ Cost for petroleum supply in period $t$ $\left(\$ 10^{3} / \mathrm{TJ}\right)$

$P_{t} \quad$ Cost for imported electricity supply in period $t\left(\$ 10^{3} / \mathrm{GWh}\right)$

$P V_{i t}^{ \pm} \quad$ Operating cost of power conversion technology $i$ for pre-regulated electricity generation in period $t\left(\$ 10^{3} / \mathrm{GWh}\right)$

Penalty cost of power conversion technology $i$ for excess electricity generation in period $t\left(\$ 10^{3} / \mathrm{GWh}\right)$

Fixed-charge cost for capacity expansion of power conversion technology $i$ in period $t\left(\$ 10^{6}\right)$

Variable cost for capacity expansion of power conversion technology $i$ in period $t$ $\left(\$ 10^{6} / \mathrm{GW}\right)$

Operating cost of control measure $j_{c}$ for pre-regulated $\mathrm{CO}_{2}$ emissions during period $t$ (\$/tonne)

Operating and penalty cost of control measure $j_{s}$ for excess $\mathrm{CO}_{2}$ emissions during period $t$ (\$/tonne)

Units of energy carrier per units of electricity production for power conversion technology $i$ in period $t$ (TJ/GWh)

Upper bound of the availability of hydropower in period $t\left(10^{3} \mathrm{TJ}\right)$

Upper bound of the availability of wind power in period $t\left(10^{3} \mathrm{TJ}\right)$

Upper bound of the availability of solar power in period $\mathrm{t}\left(10^{3} \mathrm{TJ}\right)$

Random variable of total electricity demand during period $t$ (GWh) 


\section{$R C_{i} \quad$ Residual capacity of conversion technology $i(\mathrm{GW})$ \\ $S T_{i t} \quad$ Average service time of power conversion technology $i$ in period $t(\mathrm{~h})$ \\ $X C_{i j_{c} t}^{ \pm}$ \\ $V_{t} \quad$ Peak load demand in period $t(\mathrm{GW})$ \\ $M_{i t} \quad$ Variable upper bounds for capacity expansion of power conversion technology $i$ in period $t(\mathrm{GW})$ \\ $Y C_{i j_{c} t h}^{ \pm}$ \\ $N_{i t} \quad$ Variable lower bounds for capacity expansion of power conversion technology $i$ in period $t$, and $N_{i t} \geq 0$ (GW) \\ $I N C_{i t}^{ \pm} \quad$ Units of $\mathrm{CO}_{2}$ emission per unit of electricity production for power \\ power conversion technology I needs to be undertaken when electricity demand level is $h$ in period $t$ \\ Pre-regulated amount of $\mathrm{CO}_{2}$ generated from power conversion technology $i$ to be mitigated by control measure $j_{c}$ in period $t$ (tonne) \\ Excess amount of $\mathrm{CO}_{2}$ generated from power conversion technology $i$ to be mitigated by control measure $j_{c}$ when electricity demand level is $h$ in period $t$ (tonne) \\ APPENDIX B. SOLUTION PROCEDURE OF THE PROPOSED MODEL} conversion technology $i$ in period $t$ (tonne/GWh)

$\eta_{j_{c}}^{ \pm} \quad$ Average efficiency of $\mathrm{CO}_{2}$ control measure $j_{c}(\%)$

$E C_{t}^{ \pm} \quad \mathrm{CO}_{2}$ emission allowance in period $t$ (tonne)

\section{Decision Variables}

$\begin{array}{ll}Z 1_{t}^{ \pm} & \text {Coal supply in period } t(\mathrm{TJ}) \\ Z 2_{t}^{ \pm} & \text {Natural gas supply in period } t(\mathrm{TJ}) \\ Z 3_{t}^{ \pm} & \text {Petroleum supply in period } t(\mathrm{TJ}) \\ Z 4_{t h}^{ \pm} & \begin{array}{l}\text { Imported electricity supply when } \\ \text { electricity demand level is } h \text { in period } t \\ \left(10^{3} \mathrm{GWh}\right)\end{array}\end{array}$

$W_{i t}^{ \pm} \quad$ Pre-regulated electricity generation target of power conversion technology $i$ which is promised to end-users during period $t\left(10^{3} \mathrm{GWh}\right)$

$Q_{i t h}^{ \pm} \quad$ Excess electricity generation of power conversion technology $i$ by which electricity generation target $\left(W_{k t}\right)$ is exceeded when electricity demand level is $h$ in period $t\left(10^{3} \mathrm{GWh}\right)$

$X_{\text {ith }}^{ \pm} \quad$ Continuous variables about the amount of capacity expansion of power conversion technology $i$ when electricity demand level is $h$ in period $t(\mathrm{GW})$

$Y_{i t h}^{ \pm} \quad$ Binary variables for identifying whether or not a capacity expansion action of
In the proposed model, the electricity generation targets of each conversion technology $\left(W_{i t}^{ \pm}\right)$are expressed as interval numbers; however, as the firststage decision variables, they should be identified before the related total electricity demand (i.e. random variables) are known [13]. In this study, an optimized set of $W_{i t}^{ \pm}$values will be identified by having $u_{i t}$ being decision variables; this optimized set may correspond to minimized system cost under the uncertain electricity generation targets of each conversion technology and total electricity demand [14]. In detail, let $W_{i t}^{ \pm}=W_{i t}^{-}+\Delta W_{i t} u_{i t}$, where $\Delta W_{i t}=W_{i t}^{+}-W_{i t}^{-}$and $u_{i t} \in[0,1]$. Thus, when $W_{i t}^{ \pm}$approach their lower bounds (i.e. when $u_{i t}=0$ ), a relatively low cost would be obtained; however, a higher penalty may have to be paid when the electricity demand is not satisfied. Conversely, when $W_{i t}^{ \pm}$reach their upper bounds (i.e. when $u_{i t}=1$ ), a higher cost would be generated but, at the same time, a lower risk of violating the promised targets (and thus lower penalty). Then, model (7) can be transformed into two deterministic submodels based on the interactive algorithm [17]. Because the objective is to minimize the system cost, submodel corresponding to $f^{-}$is first desired. The lower bounds of cost coefficients and total electricity demand, as well aselectricity generation shortages and capacity expansions will correspond to $f^{-}$. Thus, submodel $f^{-}$can be formulated as follows:

$$
\begin{aligned}
& \operatorname{Min} f^{-}= \\
& \sum_{t=1}^{T}\left(P E C_{t}^{-} Z 1_{t}^{-}+P E N_{t}^{-} Z 2_{t}^{-}+P E O_{t}^{-} Z 3_{t}^{-}\right)+\sum_{t=1}^{T} \sum_{h=1}^{H_{t}} p_{t h} P I E_{t}^{-} Z 4_{t h}^{-}
\end{aligned}
$$




$$
\begin{aligned}
& +\sum_{i=1}^{I} \sum_{t=1}^{T} P V_{i t}^{-}\left(W_{i t}^{-}+\Delta W_{i t} u_{i t}\right)+\sum_{i=1}^{I} \sum_{t=1}^{T} \sum_{h=1}^{H_{t}} p_{t h}\left(P V_{i t}^{-}+P P_{i t}^{-}\right) Q_{i t h}^{-} \\
& +\sum_{i=1}^{I} \sum_{t=1}^{T} \sum_{h=1}^{H_{t}} p_{t h}\left(A_{i t}^{-} Y_{i t h}^{-}+B_{i t}^{-} X_{i t h}^{-}\right) \\
& \sum_{i=1}^{I} \sum_{j_{c}=1}^{n_{c}} \sum_{t=1}^{T} C C_{j_{c} t}^{-} X C_{i j_{c} t}^{-}+\sum_{i=1}^{I} \sum_{j_{c}=1}^{n_{c}} \sum_{t=1}^{T} \sum_{h=1}^{H_{t}} p_{t h} D C_{j_{c} t}^{-} Y C_{i j_{c} t h}^{-}
\end{aligned}
$$

Subject to:

$$
\begin{aligned}
& \left(W_{1 t}^{-}+\Delta W_{1 t} u_{1 t}+Q_{1 t h}^{-}\right) F E_{1 t}^{-} \leq Z 1_{t}^{-}, \forall t ; h=1, \ldots, H_{t} \\
& \left(W_{2 t}^{-}+\Delta W_{2 t} u_{2 t}+Q_{2 t h}^{-}\right) F E_{2 t}^{-} \leq Z 2_{t}^{-}, \forall t ; h=1, \ldots, H_{t} \\
& \left(W_{3 t}^{-}+\Delta W_{3 t} u_{2 t}+Q_{3 t h}^{-}\right) F E_{3 t}^{-} \leq Z 3_{t}^{-}, \forall t ; h=1, \ldots, H_{t} \\
& \left(W_{4 t}^{-}+\Delta W_{4 t} u_{4 t}+Q_{4 t h}^{-}\right) F E_{4 t}^{+} \leq U P H_{t}^{-}, \forall t ; h=1, \ldots, H_{t} \\
& \left(W_{5 t}^{-}+\Delta W_{5 t} u_{5 t}+Q_{5 t h}^{-}\right) F E_{5 t}^{+} \leq U P W_{t}^{-}, \forall t ; h=1, \ldots, H_{t} \\
& \left(W_{6 t}^{-}+\Delta W_{6 t} u_{6 t}+Q_{6 t h}^{-}\right) F E_{6 t}^{+} \leq U P S_{t}^{-}, \forall t ; h=1, \ldots, H_{t} \\
& \sum_{i=1}^{I}\left(W_{i t}^{-}+\Delta W_{i t} u_{i t}+Q_{i t h}^{-}+Z 4_{t h}^{-}\right) \geq d_{t h}^{-}, \forall t ; h=1, \ldots, H_{t} \\
& W_{i t}^{-}+\Delta W_{i t} u_{i t}+Q_{i t h}^{-} \leq\left(R C_{i}+\sum_{i=1}^{t} X_{i t h}^{-}\right) S T_{i t}^{-}, \forall i, t ; h=1, \ldots, H_{t} \\
& W_{i t}^{-}+\Delta W_{i t} u_{i t} \geq Q_{i t h}^{-} \geq 0, \forall i, t ; h=1, \ldots, H_{t} \\
& \sum_{i=1}^{I}\left(R C_{i}+\sum_{i=1}^{t} X_{i t h}^{-}\right) \geq V_{t}^{-}, \forall t ; h=1, \ldots, H_{t} \\
& Y_{i t h}^{-}\left\{\begin{array}{l}
=1, \text { if capacity expansion is undertaken } \\
=0 \text {, if otherwise } \quad, \forall i, t ; h=1, \ldots, H_{t}
\end{array}\right. \\
& N_{i t} \leq X_{i t h}^{-} \leq M_{i t} Y_{i t h}^{-}, \forall i, t ; h=1, \ldots, H_{t} \\
& \left(W_{i t}^{-}+\Delta W_{i t} u_{i t}\right) I N C_{i t}^{-} \leq \sum_{j_{c}}^{n_{c}} X C_{i j_{c} t}^{-}, \forall i ; t \\
& Q_{i t h}^{-} I N C_{i t}^{-} \leq \sum_{j_{c}}^{n_{c}} Y C_{i i_{c} t h}^{-}, \forall i ; t ; h=1, \ldots, H_{t} \\
& \sum_{i=1}^{I} \sum_{j_{c}=1}^{n_{c}}\left(1-\eta_{j_{c}}^{+}\right)\left(X C_{i j_{c} t}^{-}+Y C_{i j_{c} t h}^{-}\right) \leq E C_{t}^{-}, \forall t ; h=1, \ldots, H_{t}
\end{aligned}
$$

$$
\begin{aligned}
& Z 1_{t}^{-}, Z 2_{t}^{-}, Z 3_{t}^{-}, Z 4_{t h}^{-}, W_{i t}^{-}, Q_{i t h}^{-}, X C_{i j_{c} t}^{-}, \\
& Y C_{i j_{c} t h}^{-} \geq 0, \forall i ; j_{c} ; t ; h=1, \ldots, H_{t}
\end{aligned}
$$

where $Q_{i t h}^{-}, \quad X_{i t h}^{-}, \quad X C_{i j_{c} t}^{-}$and $Y C_{i j_{c} t h}^{-}$are continuous decision variables, and $Y_{i t h}^{-}$are binary ones. Solution for $f^{-}$provides the extreme lower bound of system cost under uncertain inputs. Let $Q_{i t h o p t}^{-}, X_{i t h o p t}^{-}, X C_{i j_{c} t \mathrm{opt}}^{-}$, $Y C_{i j_{c} \text { thopt }}^{-}, Y_{i t h o p t}^{-}$, and $f_{\text {opt }}^{-}$be solutions of sub model (9). Then the optimized electricity generation targets would be $W_{i t \mathrm{opt}}^{ \pm}=W_{i t}^{-}+\Delta W_{i t} u_{i t \mathrm{opt}}$. Therefore, sub model (10) corresponding to the upper bound of the objective function value $\left(f^{+}\right)$can be formulated as follows:

$$
\begin{aligned}
& \operatorname{Min} f^{+}= \\
& \sum_{t=1}^{T}\left(P E C_{t}^{+} Z 1_{t}^{+}+P E N_{t}^{+} Z 2_{t}^{+}+P E O_{t}^{+} Z 3_{t}^{+}\right)+\sum_{t=1}^{T} \sum_{h=1}^{H_{t}} p_{t h} P I E_{t}^{+} Z 4_{t h}^{+} \\
& +\sum_{i=1}^{I} \sum_{t=1}^{T} P V_{i t}^{+} W_{i t \mathrm{opt}}+\sum_{i=1}^{I} \sum_{t=1}^{T} \sum_{h=1}^{H_{t}} p_{t h}\left(P V_{i t}^{+}+P P_{i t}^{+}\right) Q_{i t h}^{+} \\
& +\sum_{i=1}^{I} \sum_{t=1}^{T} \sum_{h=1}^{H_{t}} p_{t h}\left(A_{i t}^{+} Y_{i t h}^{+}+B_{i t}^{+} X_{i t h}^{+}\right) \\
& \sum_{i=1}^{I} \sum_{j_{c}=1}^{n_{c}} \sum_{t=1}^{T} C C_{j_{c} t}^{+} X C_{i j_{c} t}^{+}+\sum_{i=1}^{I} \sum_{j_{c}=1}^{n_{c}} \sum_{t=1}^{T} \sum_{h=1}^{H_{t}} p_{t h} D C_{j_{c} t}^{+} Y C_{i j_{c} t h}^{+}
\end{aligned}
$$

Subject to:

$$
\begin{aligned}
& \left(W_{1 t \mathrm{opt}}+Q_{1 t h}^{+}\right) F E_{1 t}^{+} \leq Z 1_{t}^{+}, \forall t ; h=1, \ldots, H_{t} \\
& \left(W_{2 t \mathrm{opt}}+Q_{2 t h}^{+}\right) F E_{2 t}^{+} \leq Z 2_{t}^{+}, \forall t ; h=1, \ldots, H_{t} \\
& \left(W_{3 t \mathrm{opt}}+Q_{3 t h}^{+}\right) F E_{3 t}^{+} \leq Z 3_{t}^{+}, \forall t ; h=1, \ldots, H_{t} \\
& \left(W_{4 t \mathrm{opt}}+Q_{4 t h}^{+}\right) F E_{4 t}^{-} \leq U P H_{t}^{+}, \forall t ; h=1, \ldots, H_{t} \\
& \left(W_{5 t \mathrm{opt}}+Q_{5 t h}^{+}\right) F E_{5 t}^{-} \leq U P W_{t}^{+}, \forall t ; h=1, \ldots, H_{t} \\
& \left(W_{6 t \mathrm{opt}}+Q_{6 t h}^{+}\right) F E_{6 t}^{-} \leq U P S_{t}^{+}, \forall t ; h=1, \ldots, H_{t} \\
& \sum_{i=1}^{I}\left(W_{i t \mathrm{opt}}+Q_{i t h}^{+}+Z 4_{t h}^{+}\right) \geq d_{t h}^{+}, \forall t ; h=1, \ldots, H_{t} \\
& W_{i t \mathrm{opt}}+Q_{i t h}^{+} \leq\left(R C_{i}+\sum_{i=1}^{t} X_{i t h}^{+}\right) S T_{i t}^{+}, \forall i, t ; h=1, \ldots, H_{t}
\end{aligned}
$$




$$
\begin{aligned}
& W_{i t \mathrm{opt}} \geq Q_{i t h}^{+} \geq 0, \forall i, t ; h=1, \ldots, H_{t} \\
& \sum_{i=1}^{I}\left(R C_{i}+\sum_{i=1}^{t} X_{i t h}^{+}\right) \geq V_{t}^{+}, \forall t ; h=1, \ldots, H_{t} \\
& Y_{i t h}^{+}\left\{\begin{array}{l}
=1, \text { if capacity expansion is undertaken } \\
=0, \text { if otherwise } \quad, \forall i, t ; h=1, \ldots, H_{t}
\end{array}\right. \\
& N_{i t} \leq X_{i t h}^{+} \leq M_{i t} Y_{i t h}^{+}, \forall i, t ; h=1, \ldots, H_{t} \\
& W_{i t \mathrm{opt}} I N C_{i t}^{+} \leq \sum_{j_{c}}^{n_{c}} X C_{i j_{c} t}^{+}, \forall i ; t \\
& Q_{i t h}^{+} I N C_{i t}^{+} \leq \sum_{j_{c}}^{n_{c}} Y C_{i j_{c} t h}^{+}, \forall i ; t ; h=1, \ldots, H_{t} \\
& \sum_{i=1}^{I} \sum_{j_{c}=1}^{n_{c}}\left(1-\eta_{j_{c}}^{-}\right)\left(X C_{i j_{c} t}^{+}+Y C_{i j j_{c} t h}^{+}\right) \leq E C_{t}^{+}, \forall t ; h=1, \ldots, H_{t} \\
& Z 1_{t}^{+} \geq Z 1_{t}^{-}, \forall t \\
& Z 2_{t}^{+} \geq Z 2_{t}^{-}, \forall t \\
& Z 3_{t}^{+} \geq Z 3_{t}^{-}, \forall t \\
& Z 4_{t h}^{+} \geq Z 4_{t h}^{-}, \forall t ; h=1, \ldots, H_{t} \\
& Q_{i t h}^{+} \geq Q_{i t h}^{-}, \forall i ; t ; h=1, \ldots, H_{t} \\
& Y_{i t h}^{+} \geq Y_{i t h}^{-}, \forall i ; t ; h=1, \ldots, H_{t} \\
& X_{i t h}^{+} \geq X_{i t h}^{-}, \forall i ; t ; h=1, \ldots, H_{t} \\
& X C_{i j_{c} t}^{+} \geq X C_{i j_{c} t}^{-}, \forall i ; j_{c} ; t ; h=1, \ldots, H_{t} \\
& Y C_{i j_{c} t h}^{+} \geq Y C_{i j_{c} t h}^{-}, \forall i ; j_{c} ; t ; h=1, \ldots, H_{t}
\end{aligned}
$$

where $Q_{i t h}^{+}, X_{i t h}^{+}, X C_{i j_{c} t}^{+}, Y C_{i j_{c} t h}^{+}$and $Y_{i t h}^{+}$are decision variables. Let $Q_{i t h o p t}^{+}, X_{i t h o p t}^{+}, X C_{i j_{c} \text { topt }}^{+}, Y C_{i j_{c} t h o p t}^{+}, Y_{i t h o p t}^{+}$and $f_{\text {opt }}^{+}$be solutions of sub model (10).Thus, we have solutions for the proposed model under the optimized electricity generation targets (i.e. $W_{i t \mathrm{opt}}^{ \pm}=W_{i t}^{-}+\Delta W_{i t} u_{i t \mathrm{opt}}$ ) as follows:

$$
Q_{\text {ithopt }}^{ \pm}=\left[Q_{\text {ithopt }}^{-}, Q_{\text {ithopt }}^{+}\right], \forall i, t ; h=1, \ldots, H_{t}
$$

$$
\begin{aligned}
& Y_{i t h \mathrm{opt}}^{ \pm}=\left[Y_{i t h \mathrm{opt}}^{-}, Y_{i t h \mathrm{opt}}^{+}\right], \forall i, t ; h=1, \ldots, H_{t} \\
& X_{i t h \mathrm{opt}}^{ \pm}=\left[X_{i t h \mathrm{opt}}^{-}, X_{i t h \mathrm{opt}}^{+}\right], \forall i, t ; h=1, \ldots, H_{t} \\
& X C_{i j_{c} t \mathrm{opt}}^{ \pm}=\left[X C_{i j_{c} t \mathrm{opt}}^{-}, X C_{i j_{c} t \mathrm{opt}}^{+}\right], \forall i, j_{c}, t \\
& Y C_{i j_{c} t h \mathrm{opt}}^{ \pm}=\left[Y C_{i j_{c} t h \mathrm{opt}}^{-}, Y C_{i j_{c} t h \mathrm{opt}}^{+}\right], \forall i, j_{c}, t ; h=1, \ldots, H_{t} \\
& f_{\mathrm{opt}}^{ \pm}=\left[f_{\mathrm{opt}}^{-}, f_{\mathrm{opt}}^{+}\right]
\end{aligned}
$$

\section{REFERENCES}

[1] Saysel AK, Hekimoğlu M. Exploring the options for carbon dioxide mitigation in Turkish electricpower industry: System dynamics approach. Energ Policy 2014; 60: 675-86. http://dx.doi.org/10.1016/j.enpol.2013.04.053

[2] Suo MQ, Li YP, Huang GH, Deng DL, Li YF. Electric power system planning under uncertainty using in exact inventory non-linear programming method. J Environ Inform 2013; 22: 49-67.

http://dx.doi.org/10.3808/jei.201300245

[3] Chen ZM, Chen GQ, Chen B. Embodied carbon dioxide emission by the globalized economy: a systems ecological input-output simulation. J Environ Inform 2013; 21: 35-44. http://dx.doi.org/10.3808/jei.201300230

[4] Krishna PGS, Santanu B, Raymond RT. Power system planning with emission constraints: Effects of CCS retrofitting. Process Saf Environ 2014; 92: 447-55. http://dx.doi.org/10.1016/j.psep.2014.02.010

[5] Li YP, Huang GH. Electric-power systems planning and green house-gas emission management under uncertainty. Energ Convers Manage 2012; 57: 173-82. http://dx.doi.org/10.1016/j.enconman.2011.12.018

[6] Nürnberg R, Römisch W. A two-stage planning model for power scheduling in a hydro-thermal system under uncertainty. Optim Eng 2002; 3: 355-78. http://dx.doi.org/10.1023/A:1021531823935

[7] Bagajewicz M, Barbaro AF. Financial risk management in the planning of energy recovery in the total site. Ind Eng Chem Res 2003; 42: 5239-48. http://dx.doi.org/10.1021/ie020389u

[8] Albornoz VM, Benario P, Rojas ME. A two-stagestochastic integer programming model for a thermal power system expansion. Int Toper Res 2004; 11: 243-57.

[9] Floros N, Vlachou A. Energy demand and energy related CO2 emissions in Greek manufacturing: Assessing the impact of a carbon tax. Energ Econ 2005; 27: 387-413. http://dx.doi.org/10.1016/j.eneco.2004.12.006

[10] Lin QG, Huang GH, Bass B, Qin XS. IFTEM: An intervalfuzzy two-stage stochastic optimization model for regional energy systems planning under uncertainty. Energ Policy 2009; 37: 868-78.

http://dx.doi.org/10.1016/j.enpol.2008.10.038

[11] Lin QG, Huang GH. An in exact two-stage stochastic energy systems planning model for managing green house gas emission at a municipal level. Energ 2010; 35: 2270-80. http://dx.doi.org/10.1016/j.energy.2010.01.042

[12] Chen WT, Li YP, Huang GH, Chen X, Li YF. A two-stage in exact-stochastic programming model for planning carbon dioxide emission trading under uncertainty. Appl Energ 2010; 87: 1033-47. http://dx.doi.org/10.1016/j.apenergy.2009.09.016 
[13] Chen C, Li YP, Huang GH, Zhu Y. An in exact robust nonlinear optimization method for energy systems planning under uncertainty. Renew Energ 2012; 47: 55-66. http://dx.doi.org/10.1016/j.renene.2012.04.007

[14] Chen C, Li YP, Huang GH. An in exact robust optimization method for supporting carbon dioxide emissions management in regional electric-power systems. Energ Econ 2013; 40: 441-56.

http://dx.doi.org/10.1016/j.eneco.2013.07.022

[15] Li YP, Huang GH. A stochastic-fuzz y programming model with soften constraints for electricity generation planning with green house-gas abatement. Int J Energ Res 2013; 37: 84356.

http://dx.doi.org/10.1002/er.2885

[16] Ford A. Simulation scenarios for rapid reduction in carbon dioxide emissions in the western electricity system. Energ Policy 2008; 36: 443-55.

http://dx.doi.org/10.1016/j.enpol.2007.09.023
[17] Li YP, Huang GH, Yang ZF, Nie SL. An integrated two-stage optimization model for the development of long-term wastemanagement strategies. Sci Total Environ2008; 392: 175-86. http://dx.doi.org/10.1016/j.scitotenv.2007.11.028

[18] Birge JR, Louveaux FV. Introduction to Stochastic Programming. New York, NY: Springer; 1997.

[19] Ahmed S, Tawarmalani M, Sahinidis NV. A finite branch-andbound algorithm for two-stage stochastic integer programs. Math Program 2004; 100: 355-77. http://dx.doi.org/10.1007/s10107-003-0475-6

[20] Huang GH, Baetz BW, Patry GG. An interval linear programming approach for municipal solid waste management planning under uncertainty. Civ Eng Environ Syst 1992; 9: 319-35. http://dx.doi.org/10.1080/02630259208970657

[21] Li W, Huang GH, Dong C, Liu Y. An in exact fuzzy programming approach for power coal blending. J Environ Inform 2013; 21: 112-8. http://dx.doi.org/10.3808/jei.201300238 